\title{
Chang $\mathbf{Y}_{\text {IN }} \mathbf{C H I A}$
}

\section{Estudo da maturação da resposta vascular da artéria}

\section{mesentérica superior em recém-nascidos prematuros através}

\author{
do dopplerfluxometria
}

Tese apresentada à Faculdade de

Medicina da Universidade de São Paulo para obtenção do título de Doutor em Ciências

Área de concentração: Pediatria

Orientador: Dr. Mário Cícero Falcão

SÃO PAULO

2009 


\title{
Chang $\mathbf{Y}_{\text {IN }} \mathbf{C H I A}$
}

\section{Estudo da maturação da resposta vascular da artéria}

\section{mesentérica superior em recém-nascidos prematuros através}

\author{
do dopplerfluxometria
}

Tese apresentada à Faculdade de

Medicina da Universidade de São Paulo para obtenção do título de Doutor em Ciências

Área de concentração: Pediatria

Orientador: Dr. Mário Cícero Falcão

SÃO PAULO

2009 


\section{DEDICATÓRIA}

Este trabalho é dedicado àqueles que acreditaram em mim, àqueles que ajudaram a construí-lo e àqueles que virão a obter proveito dele;

Dedico àqueles que me dão motivação para me tornar uma pessoa cada vez melhor : meu marido, Renato; meus filhos, Julia, Christian e Victor; e meus pais;

Dedico aos recém-nascidos ...,

ao futuro do conhecimento...,

à minimização do sofrimento...,

à supremacia da ética.

Dedico à vida ..., na sua arte e no seu conhecimento! 


\title{
AGRADECIMENTOS
}

\author{
Agradeço ao
}

\section{Dr. Mário Cícero Falcão,}

\author{
meu Orientador, \\ pela sua amizade incondicional, \\ pela quietude e sabedoria ao me escutar, \\ pelo esbravejar e sinceridade ao me aconselhar, \\ por me ensinar que não vale o conhecimento \\ sem divulgar, \\ que não vale queixas \\ sem o efetuar, \\ vale o concretizar.
}

O meu muito obrigado por acreditar. 


\title{
AGRADECIMENTOS
}

\author{
Agradeço ao
}

\section{Dr. Joaquim Eugênio Bueno Cabral}

\author{
pelo exemplo de pessoa, \\ pelo exemplo de Luta e vitória \\ na preservação de princípios e valores de retidão \\ pela sua ética inabalável; \\ pelos seus ensinamentos \\ e pelos seus muitos conselhos.
}

O meu muito obrigado por ser. 


\title{
AGRADECIMENTOS
}

Aos Chefes do Berçário da Maternidade São Luiz:

Dr. Luiz Carlos Bueno Ferreira , Dr. Sérgio de Souza Ayres e

Dr. Joaquim Eugênio Bueno Cabral,

\author{
por reconhecer a importância deste trabalho \\ e por permitir a sua realização; \\ pelo fiel e constante incentivo.
}




\title{
AGRADECIMENTOS
}

\author{
A Deus, Autor da Vida.
}

A meus pais, que nunca tiveram a oportunidade, mas sempre souberam da importância do conhecimento e tiveram a sabedoria de transmití-la.

Ao meu marido, Renato, pelo apoio incondicional.

Aos meus filhos, Julia, Christian e Victor, minha inspiração para cada dia ser melhor pessoa, mãe e médica.

A minha irmã Min, exemplo de perseverança e sucesso profissional.

Ao meu irmão e à minha cunhada Milena, pelo suporte nos momentos de dificuldade e pelo cuidado que têm com os meus filhos. Ao Danilo, pela alegria do seu nascimento.

Ao Dr. Luiz Guilherme de Carvalho Hartmann, pela realização dos exames, pelo auxílio no entendimento e interpretação dos exames ultrassonográficos;

Aos Drs. Mário de Melo Galvão Filho e Luiz de Abreu Júnior

Aos Chefes do Berçário da Maternidade São Luiz: Dr. Luiz Carlos Bueno Ferreira, Dr. Sérgio de Souza Ayres e Dr. Joaquim Eugênio Bueno Cabral. E aos Drs. Eduardo Braun Ferreira, Miriam Rika Taguchi e Graziela Lopes Del Ben pelo apoio e auxílio na solicitação dos exames. Ao Dr. Paulo Schiller pela correção dos textos em inglês.

Prof. Dr. Flávio Adolfo Costa Vaz e Profa Dra Sandra J.E. Grisi, chefes do Departamento de Pediatria - FMUSP

Ao Prof. Dr. José Lauro de Araújo Ramos

Ao Prof. Dr. Cláudio Leone e a Profa ${ }^{2} r^{a}$ Cléa Rodrigues Leone, porque são verdadeiramente professores, pelo apoio pessoal e profissional.

A Profa $\operatorname{Dr}^{a}$ Thelma Suely Okay, pelo apoio e compreensão nos momentos difíceis. A $\mathscr{D r}^{a}$ Lílian dos Santos Rodrigues Sadecke $\mathscr{D r} r^{a}$ Marta Maria G. B. Mataloun. $\operatorname{Dr}^{a}$ Maria Esther Jurvest Ceccon, $\operatorname{Dr}^{a}$ Yu Kar Lin Koda, Dr. Marcelo Valente Dr $r^{a}$ Simone Shibao 
Dra Vera Lúcia Jornada Krebs, $\boldsymbol{D r}^{a}$ Valdenise Laurindo Tuma Cafil, Dra Alice D'Agostini Deutch

Dr. Adolfo Wenjaw Liao

Ao Dr. Miguel Borrelli Neto, sempre amigo e pelo cuidado que têm com os meus filhos.

A Dra. Domenique Z. Orkov, pela amizade inestimável.

Ao Dr. Pedro Paulo do Amaral Corrêa, meu sempre muito amigo;

$\operatorname{Dr}^{a}$ Ana Cristina Pinheiro Mancini,

$\operatorname{Dr}^{a}$ Renata de Arruda $\mathscr{D}^{\prime}$ Andrea,

$\operatorname{Dr}^{a}$ Ana Cristina Pinheiro Tancredi, $\operatorname{Dr}^{a}$ Lourdes de F. Gomes,

Dra Maria Helena P. E. Giangrande, Dr. Renato Pessoa de Carvalho,

Dra. Maria Aurora Brandão, Dr. Beno Petlik,

Dra. Sílvia T. Rielli, Dra. Isabel Prada Cáceres,

Dra Laura Emília Monteiro Bigelli Cardoso, Dra. Patrícia Prado Durante,

$\operatorname{Dr}^{a}$ Renata Monteiro de Araújo, Dra Fabiana Iglesias de Carvalho,

Edi Toma, Carla Marques Nicolau;

Aos meus colegas do Berçário Anexo à Maternidade do HCFMUSP,

Aos meus colegas do Berçário da Maternidade São Luiz,

À equipe de enfermagem do Berçário Anexo à Maternidade do HCFMUSP,

À equipe de enfermagem do Berçário da Maternidade São Luiz, pelo apoio e pela valorização deste trabalho no seu meio; em especial à Carolina e Cida (escriturárias)e às enfermeiras Regina Mota e Fernanda.

A Adriana, Denize e Solange, da secretaria de pós-graduação - ICR - HCFMUSP,

A Márcia e Regina, da secretaria médica - ICR - HCFMUSP,

A Marisa Kazue Umetsu e sua equipe da Biblioteca do Instituto da CriançaHCFMUSP, pela revisão das referências bibliográficas. 


\section{SUMÁRIO}

Lista de abreviaturas, siglas e símbolos

Lista de quadros, tabelas, gráficos e figuras

Resumo

Summary

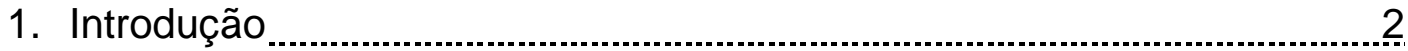

1.1. Embriologia

1.2. Fisiologia da regulação do fluxo sanguíneo intestinal ..............

1.3. Peculiaridades da circulação mesentérica do recém-nascido ............9

1.4. Mecanismos de regulação da circulação intestinal em $\mathrm{RN}$.................14

1.5. Resposta vascular da circulação intestinal em recém-nascidos _......18

1.6. Implicações das características da circulação intestinal na patogênese da enterocolite necrosante ................................................ 19

1.7. Dopplerfluxometria da artéria mesentérica superior ……...................... 24

1.8. Hipótese

2. Objetivos

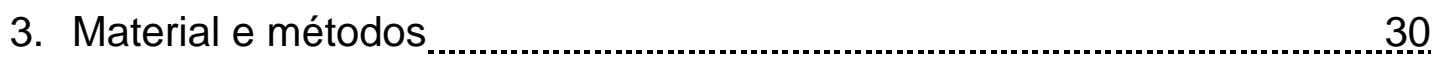

3.1. Grupos de estudo

3.2. Dopplerfluxometria da artéria mesentérica superior ………….....31 


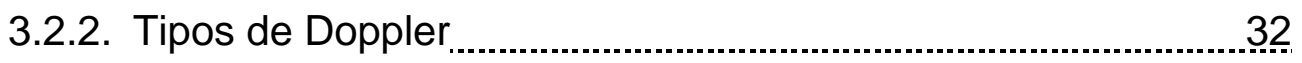

3.2.3. Interpretação dos resultados dopplervelocimétricos ..................34 Índice de resistência Índice de pulsatilidade

4. Resultados

4.1. Descrição e caracterização dos grupos de estudo ..................................

4.2. Resultados da dopplerfluxometria

Índice de resistência

Índice de pulsatilidade

Pico de velocidade sistólica

Pico de velocidade diastólica final

5. Discussão

6. Conclusões 65

7. Considerações finais

8. Anexos 70

9. Referências 80 
LISTA DE ABREVIATURAS, SIGLAS E SÍMBOLOS

$\begin{array}{ll}\text { RN } & \text { recém-nascido } \\ \text { RNPT } & \text { recém-nascido pré-termo } \\ \text { ECN } & \text { enterocolite necrosante } \\ \text { PAF } & \text { fator ativador de plaquetas } \\ \text { ET-1 } & \text { endotelina-1 } \\ \text { ETA } & \text { receptor de endotelina A } \\ \text { ETB } & \text { receptor de endotelina B } \\ \text { NO } & \text { óxido nítrico } \\ \text { PKC } & \text { proteína C quinase } \\ \text { UTI } & \text { unidade de terapia intensiva } \\ \text { EcNOS } & \text { sintetase de NO das células endoteliais } \\ \text { PIG } & \text { pequeno para a idade gestacional } \\ \text { RCIU } & \text { restrição de crescimento intra-uterino } \\ \text { HAS } & \text { hipertensão arterial sistêmica } \\ \text { USP } & \text { Universidade de São Paulo } \\ \text { HC } & \text { Hospital das Clínicas } \\ \text { FMUSP } & \text { Faculdade de Medicina da USP } \\ \text { AMS } & \text { Artéria mesentérica superior } \\ \text { IR } & \text { Índice de resistência } \\ \text { IP } & \text { Índice de pulsatilidade } \\ \text { PVS } & \text { Pico de velocidade sistólica } \\ \text { PVDF } & \text { Pico de velocidade diastólica final } \\ \text { dp } & \text { desvio padrão } \\ \text { FC } & \text { freqüência cardíaca } \\ \text { FR } & \text { freqüência respiratória } \\ \text { PAM } & \text { pressão arterial média } \\ \text { g } & \text { gramas } \\ \text { kg } & \text { kilogramas } \\ \text { ml } & \text { mililitros } \\ \text { mmHg } & \text { milímetros de mercúrio } \\ \text { min } & \text { minutos } \\ & \end{array}$




\section{LISTA DE QUADROS, TABELAS, GRÁFICOS E FIGURAS}

Figura 1- Imagem ultra-sonográfica bidimensional da região da artéria mesentérica superior em recém-nascido pré-termo no $7^{\circ}$ dia de vida

Tabela 1- Caracterização da população do estudo quanto à idade gestacional e peso de nascimento.

Tabela 2- Caracterização da população do estudo quanto às condições clínicas, hemodinâmicas, fluxo urinário e oferta hídrica

Tabela 3- Índices de resistência e de pulsatilidade no $1^{\circ}, 3^{\circ}, 7^{\circ}, 14^{\circ}, 21^{\circ}, 28^{\circ}$, $35^{\circ}, 42^{\circ}$ dias de vida, nos momentos pré e pós prandiais

Tabela 4- Picos de velocidades sistólica e diastólica final no $1^{\circ}, 3^{\circ}, 7^{\circ}, 14^{\circ}, 21^{\circ}$, $28^{\circ}, 35^{\circ}, 42^{\circ}$ dias de vida, nos momentos pré e pós prandiais

Gráfico 1- Valores médios dos índices de resistência (IR) pré e pós- prandiais, nas primeiras seis semanas de vida 45

Gráfico 2- Valores médios dos índices de pulsatilidade (IP) pré e pósprandiais, nas primeiras seis semanas de vida

Gráfico 3- Médias de picos de velocidades sistólica (PVS) pré e pós- prandiais, nas primeiras seis semanas de vida em $\mathrm{cm} / \mathrm{s}$.

Gráfico 4- Médias de picos de velocidades diastólicas final (PVDF) pré e pósprandiais, nas primeiras seis semanas de vida em $\mathrm{cm} / \mathrm{s}$ 
Resumo 


\section{Resumo}

CHANG, Y. C. Estudo da maturação da resposta vascular da artéria mesentérica superior em recém-nascidos prematuros através do dopplerfluxometria. São Paulo: Faculdade de Medicina, Universidade de São Paulo; 2009.

INTRODUÇÃO: O conhecimento de valores de normalidade do fluxo sanguíneo da artéria mesentérica superior (AMS) em recém-nascidos prematuros (RNPT) saudáveis pode prevenir quadros de intolerância alimentar e a ocorrência da enterocolite necrosante.

MÉTODOS: Com o objetivo de descrever a evolução dos índices de avaliação da dopplerfluxometria da AMS em RNPT saudáveis de idade gestacional entre 27 e 34 semanas completas, no primeiro, no terceiro, no sétimo e semanalmente $(14,21,28,35$ e 42 dias de vida), foi realizado este estudo coorte prospectivo em RNPT de idade gestacional ao nascimento entre 27 e 34 semanas completas. O exame dopplerfluxométrico foi realizado, após o consentimento livre e esclarecido dos responsáveis pelos RNPT, através do aparelho Logic Book 8C-RS (General Eletric - EUA); obtendo-se as seguintes medidas: pico de velocidade sistólica (PVS), pico de velocidade diastólica final (PVDF) e média de velocidade de fluxo; sendo, após, calculadas o Índice de Pourcelot, sendo: [pico de velocidade sistólico pico diastólico final] / pico de velocidade sistólico, que representa um índice de resistência (IR); e índice de pulsatilidade (IP). Foram excluídos: recémnascidos com instabilidade hemodinâmica; em ventilação assistida com altos parâmetros; síndromes mal-formativas; intolerância alimentar ou enterocolite necrosante; fototerapia; presença de cateteres umbilicais, persistência de canal arterial e pequenos para a idade gestacional. O exame pré-prandial foi realizado antes da alimentação (até 30 minutos) e pós-prandial entre 15 e 60 minutos após a alimentação. Foram realizados no primeiro dia (entre 6 a 24 horas de vida), no terceiro, no sétimo, e após, semanalmente até 42 dias de vida. Os resultados foram expressos em médias e desvios-padrão e descritos de maneira evolutiva.

RESULTADOS: Ao total, foram estudados 77 RNPT e realizados 125 exames. Os valores em média \pm desvio-padrão são descritos na seqüência do primeiro, terceiro, sétimo e, consecutivamente a cada semana, até 42 dias de vida; sendo: IR pré-prandial de $0,69 \pm 0,09 ; 0,67 \pm 0,15 ; 0,75 \pm 0,07$; $0,74 \pm 0,07 ; 0,75 \pm 0,07 ; 0,76 \pm 0,07 ; 0,79 \pm 0,03 ; 0,78 \pm 0,05$ e IR pós-prandial de $0,66 \pm 0,10 ; \quad 0,70 \pm 0,21 ; \quad 0,74 \pm 0,07 ; \quad 0,73 \pm 0,08 ; \quad 0,75 \pm 0,06 ; \quad 0,76 \pm 0,06$ $0,77 \pm 0,04 ; 0,77 \pm 0,03$. Os resultados de IP pré-prandial foram: $1,45 \pm 0,30$; $1,35 \pm 0,28 ; \quad 1,68 \pm 0,29 ; \quad 1,50 \pm 0,23 ; \quad 1,47 \pm 0,22 ; \quad 1,52 \pm 0,20 ; \quad 1,62 \pm 0,09$; $1,68 \pm 0,06$ e IP pós-prandial: $1,38 \pm 0,39 ; 1,40 \pm 0,29 ; 1,58 \pm 0,26 ; 1,46 \pm 0,26$; 
$1,45 \pm 0,24 ; 1,50 \pm 0,27 ; 1,58 \pm 0,10 ; 1,64 \pm 0,04$. Obtivemos PVS pré-prandial: $60,51 \pm 22,24 ; \quad 55,24 \pm 26,04 ; \quad 90,61 \pm 12,74 ; \quad 95,33 \pm 18,11 ; \quad 92,89 \pm 15,40 ;$ $96,96 \pm 12,18 ; \quad 63,18 \pm 14,08 ; \quad 58,12 \pm 9,78$ e pós-prandial: $59,60 \pm 24,14$; $110,82 \pm 32,45 ; 118,10 \pm 20,15 ; 121,95 \pm 24,18 ; 124,15 \pm 25,16 ; 126,07 \pm 18,17$; 96,68 $\pm 11,12$; 96,12 $\pm 8,98$. Quanto a PVDF pré-prandial, obtivemos: $18,85 \pm 6,09 ; 18,66 \pm 10,01 ; 20,99 \pm 8,12 ; 22,02 \pm 8,50 ; 23,04 \pm 7,89 ; 22,24 \pm 8,02$; $11,99 \pm 6,15 ; 12,05 \pm 5,12$ e PVDF pós-prandial: $20,63 \pm 6,89 ; 30,15 \pm 12,78$; $27,98 \pm 9,72 ; 29,02 \pm 10,05 ; 34,56 \pm 9,00 ; 32,02 \pm 8,45 ; 19,02 \pm 4,95 ; 21,15 \pm 3,43$. A partir dos resultados acima, demonstra-se que o fluxo sanguíneo da AMS em RNPT saudáveis apresenta uma evolução peculiar a partir do nascimento tanto dos valores basais quanto após a estimulação com a dieta, representados por uma evolução característica dos índices de resistência, melhora dos picos de velocidades sistólica e diastólica e melhora da resposta vasodilatadora após a alimentação enteral.

CONCLUSÕES: RNPT saudáveis de idade gestacional ao nascimento de 27 a 34 semanas completas apresentam uma evolução do fluxo sanguíneo da artéria mesentérica superior de maneira peculiar, do nascimento até 42 dias de vida, tanto dos valores basais quanto em resposta à alimentação. $O$ conhecimento destes valores pode indicar a dopplerfluxometria como um método preventivo de avaliação específico de cada RNPT para a introdução e progressão mais segura da alimentação, reduzindo a ocorrência de quadros gastrintestinais, melhorando os índices de morbi-mortalidade neonatal.

Descritores: 1.Recém-nascido 2.Prematuro 3.Artéria mesentérica superior/crescimento \& desenvolvimento 4.Artéria mesentérica superior/ultra-sonografia 5.Ultra-sonografia doppler 6.Enterocolite necrosante/fisiopatologia 
Summary 


\section{SUMMARY}

CHANG, Y. C. Evolution of superior mesenteric artery blood flow by means of doppler velocimetry in health premature neonates. São Paulo: Faculdade de Medicina, Universidade de São Paulo; 2008.

INTRODUCTION: The knowledge of the normal values of indices of Doppler velocimetry of the superior mesenteric artery in healthy premature neonates may help to prevent feeding intolerance situations and necrotizing enterocolitis.

METHODS: In order to describe the indices for evaluation of Doppler velocimetry of the superior mesenteric artery in healthy premature neonates with gestational age between 27 and 34 weeks, on the first, third, seventh days, and then weekly, until six weeks of life; this is a prospective cohort study. The Doppler velocimetric examination was done by means of the Logic Book 8C-RS (General Electric - USA), using a $8 \mathrm{MHz}$ imaging transducer, with the pulsed color Doppler readings being obtained by sonographic waves at $4 \mathrm{MHz}$. The neonate was kept in a supine position, with the transducer positioned in the epigastric region, immediately below the xyphoid appendix, obtaining two-dimensional images of the celiac trunk and of the superior mesenteric artery, a few millimeters after its emergence from the aorta in the sagittal plane. The flux measurements were obtained in the longitudinal direction of the vessel and at an angle of insonation between 0 and 20 degrees. The blood flow curves were recorded after a sequence of five stable measurements, with respect to the quality of the waves, and with respect to their audible characteristics; thus obtaining the following measurements: peak systolic velocity (PSV), end diastolic velocity (EDV) and average flow velocity; with the Pourcelot Index being calculated subsequently, that is: [peak of systolic velocity - end diastolic velocity / peak of systolic velocity, which represents a resitance index (RI); and pulsatility index (PI). The values obtained were expressed as averages and standard deviations. The results were stored in an Excel database, with blind analysis after the conclusion of data gathering. Uncomplicated and appropriate for gestational age premature neonates with gestational age between 27 and 34 weeks at birth were included in the study.

We adopted as criteria for exclusion from the study: neonates in unstable hemodynamic conditions; needing assisted ventilation with high parameters; large deformations or clinical syndromes; feeding intolerance or diagnosis of necrotizing enterocolitis; conditions that alter the mesenteric flow, such as: phototherapy, presence of umbilical catheters, patent ductus arteriosus and sepsis. The exams were done prior to feeding (up to 30 minutes) and after feeding (between 15 and 60 minutes). If the neonate was fasting, only one of the above parameters was measured, in order to establish behavior of the basal mesenteric flow at that moment. The exams were done on the first day (between the 6th and 24th hours of life), third, 
seventh days, and then weekly, until six weeks of life. Data are shown as the mean \pm standard deviation and described for each postnatal age group.

RESULTS: A total of 77 neonates were studied and realized 125 exams. The values of the resistance and pulsatility indices (RI and $\mathrm{PI}$ ); peaks of systolic (PSV) and final diastolic velocity (EDV) on the first, third, seventh days, and then, on sequentially for each week until six weeks of postnatal life; as mean and standard deviations, was described: RI prior to feeding were $0,69 \pm 0,09$; $0,67 \pm 0,15 ; \quad 0,75 \pm 0,07 ; \quad 0,74 \pm 0,07 ; \quad 0,75 \pm 0,07 ; \quad 0,76 \pm 0,07 ; \quad 0,79 \pm 0,03 ;$ $0,78 \pm 0,05$ and RI after feeding were $0,66 \pm 0,10 ; 0,70 \pm 0,21 ; 0,74 \pm 0,07$; $0,73 \pm 0,08 ; 0,75 \pm 0,06 ; 0,76 \pm 0,06 ; 0,77 \pm 0,04 ; 0,77 \pm 0,03$. The results of $\mathrm{PI}$ prior to feeding: $1,45 \pm 0,30 ; 1,35 \pm 0,28 ; 1,68 \pm 0,29 ; 1,50 \pm 0,23 ; 1,47 \pm 0,22$; $1,52 \pm 0,20 ; 1,62 \pm 0,09 ; 1,68 \pm 0,06$ and PI after feeding: $1,38 \pm 0,39 ; 1,40 \pm 0,29$; $1,58 \pm 0,26 ; 1,46 \pm 0,26 ; 1,45 \pm 0,24 ; 1,50 \pm 0,27 ; 1,58 \pm 0,10 ; 1,64 \pm 0,04$. The values of PSV prior to feeding were: $60,51 \pm 22,24 ; 55,24 \pm 26,04$; $90,61 \pm 12,74 ; \quad 95,33 \pm 18,11 ; \quad 92,89 \pm 15,40 ; \quad 96,96 \pm 12,18 ; \quad 63,18 \pm 14,08$; $58,12 \pm 9,78$ and after feeding: $59,60 \pm 24,14 ; 110,82 \pm 32,45 ; 118,10 \pm 20,15$; $121,95 \pm 24,18 ; 124,15 \pm 25,16 ; 126,07 \pm 18,17 ; 96,68 \pm 11,12 ; 96,12 \pm 8,98$. And the results of EDV prior to feeding: $18,85 \pm 6,09 ; 18,66 \pm 10,01 ; 20,99 \pm 8,12$; $22,02 \pm 8,50 ; 23,04 \pm 7,89 ; 22,24 \pm 8,02 ; 11,99 \pm 6,15 ; 12,05 \pm 5,12$ and EDV after feeding: $20,63 \pm 6,89 ; 30,15 \pm 12,78 ; 27,98 \pm 9,72 ; 29,02 \pm 10,05 ; 34,56 \pm 9,00$; $32,02 \pm 8,45 ; 19,02 \pm 4,95 ; 21,15 \pm 3,43$. These results shows that healthy premature neonates with gestational age between 27 and 34 weeks presents a peculiar evolution in blood flow in the superior mesenteric artery after birth, represented by the resistance patterns caracteristics, improvement in peaks of systolic and diastolic velocity, and improvement in vasodilation in response to feeding.

CONCLUSION: These results suggest for the Doppler velocimetry as specific and preventive evaluation method for each premature neonate, as a way to a safer introduction and progression of feeding, reducing the prevalence of gastrointestinal inflammatory diseases in neonates, and improving the indices of neonatal morbidity and mortality. Knowledge of blood-flow velocity in the superior mesenteric artery in uncomplicated preterm infants might provide a clue in investigating the maturation of intestinal circulation and the pathogenesis or pathophysiology of gastrointestinal diseases in newborn infants.

Key Words: 1. Infant, newborn 2. Infant, premature 3. Mesenteric artery, superior/growth \& development 4. Mesenteric artery, superior/ ultrasonography 5. Ultrasonography/ doppler 6. Enterocolitis necrotizing/physiopathology 
1. Introdução 


\section{INTRODUÇÃO}

Com os avanços da medicina perinatal, particularmente na última década, ocorre um aumento de sobrevida de recém-nascidos cada vez mais prematuros, gerando até constantes discussões sobre o limite da viabilidade fetal. Este aumento da sobrevida deve-se, principalmente, a recursos de manutenção e de tratamento de quadros respiratórios agudos específicos de recém-nascidos prematuros que outrora foram limitantes de sua sobrevivência; são de suma importância, então, o desenvolvimento da ventilação mecânica e o advento da terapêutica de reposição com o surfactante exógeno (Ikegami, 1994; Davis, 1998). Ademais, a sobrevida está intimamente relacionada ao avanço da terapia nutricional, por um lado, com o desenvolvimento da nutrição parenteral, através da formulação de soluções balanceadas que atendem ao perfil metabólico do recém-nascido prematuro; e por outro, a otimização no uso do leite materno na nutrição enteral precoce (Grassi et al., 2001; Mercier et al., 2003; Reber e Nankervis, 2004).

A partir de então, recém-nascidos de diferentes graus de imaturidade de seus órgãos e sistemas são desafiados a enfrentar situações essenciais à sua sobrevivência, tais como, exercer as funções fisiológicas: respiração, digestão, absorção de nutrientes, filtração glomerular, conversões metabólicas, dentre outras. 
A intolerância alimentar em recém-nascidos pode manifestar-se em diferentes graus de intensidade, desde a presença de resíduo gástrico ou vômitos e distensão abdominal até o quadro clássico de enterocolite necrosante, onde, no seu grau extremo, ocorre a necrose maciça dos intestinos, perfuração de alças e, conseqüentemente, pneumoperitônio; levando à necessidade de intervenção cirúrgica, aumentando a morbidade do recém-nascido acometido. Além disso, uma vez que o trato gastrointestinal representa um dos sítios de maior colonização por agentes microbianos logo após o nascimento, qualquer agressão a este local, pode levar ao transporte destes microorganismos à corrente sanguínea, fenômeno conhecido como translocação, e gerar quadros infecciosos sistêmicos, elevando a morbimortalidade neonatal. A ocorrência de intolerância alimentar está relacionada à prematuridade e ao peso de nascimento, ou seja, à maturidade do trato gastrointestinal, no que diz respeito à motilidade, produção enzimática e de sais biliares e à absorção de nutrientes; sofre influência também de condições de morbidade na gestação (insuficiência placentária), condições de nascimento ( ocorrência ou não de asfixia) (Martinussen et al., 1996; Robel-Tilling et al., 2002) e do tipo, da concentração e da osmolaridade da dieta administrada ( Carver et al., 2002).

A maturação do trato gastrointestinal pode ser dividida em três grandes componentes: tecidual-enzimático, neuronal e de fluxo sanguíneo.

O componente tecidual-enzimático corresponde à formação de vilos e de microvilos responsáveis pela produção e secreção de enzimas digestivas; promovendo a decomposição do alimento até a sua forma absorvível. Faz 
parte do desenvolvimento tecidual, a evolução da resposta imunológica intestinal.

O componente neuronal é o responsável pela estimulação nervosa que atua através de neurotransmissores, promovendo a motilidade gastrointestinal, responsável pelo transporte de alimentos até a eliminação de resíduos. Enquanto que o desenvolvimento vascular também apresenta fases, não somente quanto ao crescimento do tecido vascular propriamente dita, mas também, quanto a evolução da resposta vascular frente a diferentes estímulos, fisiológicos ou não, no decorrer do desenvolvimento fetal e neonatal.

\subsection{Embriologia}

A histogênese ocorre concomitantemente ao desenvolvimento e diferenciação anatômica dos intestinos. A diferenciação e a maturação tecidual é caracteristicamente crânio-caudal. A formação dos vilos está presente nas porções proximais do intestino na nona semana de gestação e no intestino delgado todo por volta de 14 semanas. Nesta ocasião, a superfície intestinal é formada apenas por uma fina camada de células não diferenciadas de núcleo centralizado. As criptas primitivas de Lieberkühn começam a aparecer por volta de décima semana gestacional e se completam em todo o intestino delgado por volta da vigésima semana de gestação. Os microvilos começam ser diferenciados entre terceira e décima 
semana de gestação; inicialmente curtos e espaçados irregularmente e com distintos estágios de maturidade. Por volta da vigésima semana, os microvilos já são regularmente distribuídos, os enterócitos apresentam inúmeras mitocôndrias e com glicocálices já desenvolvidos, células endócrinas contendo gastrina, secretina, colecistocinina, motilina, serotonina, somatostatina, neurotensina, peptídeo intestinal vasoativo, enteroglucagon e substância $P$ já são bem definidas, demonstrando apresentar atividades enzimática e endócrina (Langman, 1977b; Mello, 2000b).

Quanto às funções digestivas, o intestino imaturo apresenta menor capacidade de transporte de glicose e a lactase tem atividade efetiva por volta da $32^{\mathrm{a}}$ semana gestacional, apesar de apresentar atividade da maltase e da sucrase desde a $13^{a}$ semana, reduzindo a absorção de carboidratos; tem maior facilidade em absorver moléculas protéicas intactas decorrente da menor concentração local de IgA secretora, redução da proteólise e maior permeabilidade de mucosa, levando ao risco de desenvolvimento de quadros de sensibilização alimentar e danos a circulação portal; além de menor capacidade de digestão e absorção de gorduras (Bocuvalas e Balistreri, 1992; Berseth, 1998).

O intestino representa também uma importante barreira contra a entrada de microorganismos. O muco da superfície intestinal funciona como uma barreira física, além de bloquear a passagem de glicoproteínas para a corrente sanguínea; a maturação deste muco depende da integridade da mucosa e do amadurecimento enzimático das células intestinais. $\mathrm{O}$ 
componente imunológico celular está presente desde a $20^{\mathrm{a}}$ semana de gestação; as respostas contra mitógenos são detectadas na $12^{\mathrm{a}}$ semana e a antigênica contra macromoléculas, desde a $17^{\mathrm{a}}$ semana. A IgA secretora é notada desde a $22^{\mathrm{a}}$ semana. A quantidade de $\lg \mathrm{A}$ secretora e de citoquinas (interferon, fator de necrose tumoral e fator de ativação plaquetária) está deficiente em prematuros ( Bocuvalas e Balistreri, 1992; Berseth, 1998).

Quanto ao desenvolvimento neuronal, entre décima quinta e vigésima semana gestacional ocorre a migração dos neuroblastos no sentido crâniocaudal. A distribuição normal de células ganglionares está presente na vigésima-quarta semana, sendo que a maturação se dá de forma constante até os primeiros anos de vida. A redução da motilidade do trato digestivo em recém-nascidos prematuros é multifatorial, tendo influência, a imaturidade das camadas musculares, a incoordenação das ondas peristálticas e um maior número de ondas anti-peristálticas, redução da secreção hormonal e a imaturidade neuronal (Langman, 1977b; Mello, 2000b; Bocuvalas e Balistreri, 1992; Berseth, 1998).

O sistema cardiovascular é o primeiro sistema funcionante no embrião humano. Esse sistema advém do fluido angioblástico com origem no mesênquima, agregado de células mesenquimais, derivado do mesoderma. O seu desenvolvimento precoce é devido ao fato de que o embrião apresenta um rápido crescimento e logo no início, necessita de um sistema que auxilie com eficiência a obtenção de oxigênio e nutrientes e, também, a eliminação de gases e produtos do metabolismo (Langman, 1977a; Mello, 2000a). 
A angiogênese ocorre logo no início da terceira semana de gestação, sendo originária do mesoderma extra-embrionário do saco vitelínico, do pedículo do embrião e do córion, gerando a circulação placentária primitiva. A partir disso, ocorre a formação do coração e do sistema circulatório primitivo que se torna funcionante já na quinta semana de gestação. Os vasos que se formam vão se diferenciando, assumindo funções em territórios vasculares de órgão e sistemas específicos. As artérias celíacas, mesentérica superior e mesentérica inferior são derivadas das artérias vitelínicas e destas dos ramos ímpares da aorta dorsal que saem dos arcos aórticos originários do coração primitivo; estes vasos suprem os derivados do intestino anterior, médio e posterior respectivamente (Langman, 1977a; Mello, 2000a).

A artéria mesentérica superior irriga parte do intestino anterior - que dará origem a porção do duodeno - e o intestino médio no embrião. Por volta da quarta e quinta semana de gestação, o intestino médio apresenta uma comunicação com o saco vitelínico; com o crescimento de suas paredes e simultânea redução do saco vitelínico, o intestino médio adquire a forma de uma alça, onde a porção ventral persiste a comunicação com o saco vitelínico por meio de um estreito canal - o pedúnculo do saco vitelínico ou o ducto vitelínico - separando a alça em porção cranial e caudal, sendo fixadas à parede abdominal por mesentério curto. Entre estas duas porções, ocorre na espessura do mesentério dorsal, como se fosse um eixo, a artéria mesentérica superior. O ramo cefálico do intestino médio primitivo é responsável pela formação da porção final do duodeno, do jejuno e maior 
parte do íleo; e o ramo caudal, formará a porção terminal do íleo, do ceco, apêndice, colon ascendente e dois terços proximais do colon transverso. Das artérias são originadas ramificações em arcos que lançam segmentos para o interior da parede intestinal, onde formam colaterais que dão origem anastomoses fazendo ligações ao longo de todo o intestino (Langman, 1977a; Mello, 2000a).

\subsection{Fisiologia da regulação do fluxo sanguíneo intestinal}

O fluxo sanguíneo intestinal no recém-nascido é regulado por mecanismos intrínsecos e extrínsecos, assim como por substâncias vasoativas circulantes (Weir et al., 1999). Alterações de velocidade e das características deste fluxo podem ser relacionadas a fatores de morbidade perinatal (Robel-Tilling et al., 2004).

A regulação do fluxo sanguíneo no território mesentérico ocorre em dois pontos: nas arteríolas e no esfíncter pré-capilar; e em dois níveis de controle: intrínseco e extrínseco. O controle intrínseco é dependente da pressão arterial de oxigênio; a vasodilatação ocorre como resposta a oclusão do fluxo local (hiperemia reacional) ou a alimentação enteral (hiperemia funcional) e envolve mudanças no tônus vascular tanto ao nível arteriolar como pré-capilar. A regulação extrínseca é mediada pelo estímulo simpático dos nervos esplâncnicos e sofre influência de fatores circulantes endógenos e exógenos como hormônios, histamina e prostaglandinas, além de componentes da dieta enteral. Por outro lado, há situações em que os 
dois mecanismos se interferem, conhecido como escape autorregulatório, quando o fluxo sanguíneo mesentérico é comprometido pelo estímulo de nervos peri-arteriolares (extrínseca) e, em poucos minutos, este fluxo é restaurado através da regulação intrínseca (Langman, 1977a; Berseth, 1998; Mello, 2000a).

\subsection{Peculiaridades da circulação mesentérica no recém-nascido}

A teoria da isquemia intestinal relacionada à redistribuição do fluxo sanguíneo como patogênese da enterocolite necrosante (ECN) tem sido inicialmente proposta por Lloyd em 1969. Esta redistribuição teria origem na resposta neurogênica frente à redução do débito cardíaco, levando ao comprometimento dos órgãos esplâncnicos com necrose intestinal e perfuração (Lloyd, 1969; Nowicki, 2005).

O controle do fluxo sanguíneo intestinal ocorre em dois níveis: no esfíncter pré-capilar que regula o número de capilares perfundidos e ao nível da resistência arteriolar. O esfíncter pré-capilar responde conforme a saturação de oxigênio do sangue local, enquanto que a resistência arteriolar é controlada por mecanismos neurogênicos e por estímulo adrenérgico (Granger e Shepherd, 1979; Nowicki e Nankervis,1994).

Outro fator que interfere na perfusão intestinal é a policitemia, sendo inicialmente demonstrada por LeBlanc em 1984. A policitemia leva à hiperviscosidade sanguínea, gerando redução da velocidade do fluxo 
sanguíneo local, podendo reduzir a oxigenação intestinal em até 50\% (Nowicki e Nankervis,1994).

A enterocolite necrosante é uma doença da infância precoce, sendo assim, pode-se supor que condições fisiológicas intestinais são peculiares do recém-nascido, assim como, fatores circulatórios fisiológicos do intestino do recém-nascido são dependentes da idade.

Primeiras observações a respeito de características fisiológicas circulatórias do intestino do recém-nascido foram feitas por Edelstone e Holzman em 1981, seguido por Crissinger e cols. em 1988. Estes autores demonstraram, em modelos animais, que o intestino do recém-nascido apresenta maior consumo de oxigênio imediatamente ao nascimento até o final do primeiro mês de vida. Este aumento é necessário para atender a demanda necessária para os processos digestivos do intestino, assim como para o seu crescimento; fazendo parte do preparo para que os intestinos tornem a única via de aquisição de nutrientes. Histologicamente, observa-se também um aumento de capilares perfusionais, aumentando a superfície de difusão do oxigênio aos intestinos. Estas características tornam o intestino do RN mais suscetíveis a hipóxia.

Ademais, o intestino do RN não apresenta uma resposta adequada a hipotensão sistêmica ou à hipóxia (Granger et al., 1982; Kvietys e Granger, 1982); não é capaz de reduzir a sua resistência vascular local e relaxar os esfíncteres pré-capilares de maneira satisfatória, necessitando de recorrer ao mecanismo de escape auto-regulatório, mediado por inervação simpática, para aumentar o fluxo sanguíneo local nestas condições. 
Os mecanismos fisiológicos de regulação do tônus vascular do intestino do recém-nascido são descritos à seguir. As células endoteliais são responsáveis pela produção de agentes vasoativos que atuam no tônus da musculatura lisa vascular local. Um destes agentes é o óxido nítrico, responsável pelo relaxamento do tônus vascular. A produção de óxido nítrico basal é maior em animais mais jovens (Rees et al.,1989 e Nowicki e Edwards, 1992). Assim, processos inflamatórios locais ou sistêmicos (sepse) com danos na vasculatura local, podem levar a redução do fluxo sanguíneo com comprometimento da resposta vascular fisiológica, agravando o processo da lesão intestinal (Kempley e Murdoch, 2000).

Em condições habituais, após um período de deprivação de oxigênio, a vasculatura regional responde de maneira danosa na reperfusão (Crissinger et al., 1992), levando a um aumento de produção de radicais livres (Parks et al., 1982), provocando uma lesão extensa do tecido acometido. Este processo ocorre por meio de dois mecanismos. Por um lado, ocorre a ativação de neutrófilos que ficam aderidas ao endotélio vascular que se concentram em maior número durante a isquemia (Granger et al., 1989 e Grisham et al., 1986), e por outro, as xantinas oxidases ligadas ao tecido geram radicais livres a partir da degradação enzimática da hipoxantina (Granger et al., 1981 e Parks et al.,1982). No RN, o intestino tem uma capacidade limitada de gerar radicais livres; possui uma atividade da xantina oxidase mais baixa e a quantidade de neutrófilos aderidos ao endotélio são menor (Crissinger et al., 1989). Porém, este mecanismo de lesão pode estar exacerbado em recém-nascidos expostos a dieta enteral 
formulado, sendo relacionado ao conteúdo lipídico deste (Crissinger et al.,1992).

O fator ativador de plaquetas (PAF) é um fosfolípide produzido por diversos tecidos, inclusive o parênquima intestinal e o endotélio vascular, sendo induzido por hipóxia e possui uma atividade vasoconstrictora potente (Ewer, 2002; Amer et al., 2004). A sua ação na microvasculatura intestinal pode ser direta ou através da liberação de leucotrieno $\mathrm{C} 4$, também potente vasoconstrictor (Hsueh et al., 1986 a b).

$\mathrm{Na}$ vida intra-uterina, a redução do fluxo na veia umbilical, e conseqüente hipoxemia do sangue que chega ao embrião, geram o fenômeno da redistribuição do fluxo sanguíneo, com vasodilatação do território cerebral e redução do aporte sanguíneo aos demais órgãos e sistemas. A redução do fluxo mesentérico gerando aumento dos índices de resistência, pode ser indicativo de risco da gestação (Bhat et al., 2002). Dependendo do tempo que a injúria causada pela hipoxemia persistir, esta vasoconstricção do leito mesentérico pode-se manter até a vida extrauterina, levando a condições de morbidade ao recém-nascido (Korszun et al., 2002). Estas situações podem ser representadas em casos de doenças maternas na gestação, tais como: hipertensão arterial, trombofilias, restrição de crescimento intra-uterino e infecções.

Logo após o nascimento, o fluxo mesentérico pode estar reduzido pelo fato do RN estar em condição de circulação transicional, onde o ducto arterioso ainda é patente, esta condição geralmente persiste entre três a 
cinco dias de vida (Coombs et al., 1992; Maruyama et al., 1999), em situações onde exista a manutenção do estado hemodinâmico adequado.

Situações clínicas que podem alterar o fluxo sanguíneo mesentérico são: comprometimento do estado hemodinâmico do RN, como o choque ou a hipotensão gera a redistribuição do fluxo sistêmico (Agata et al., 1994), o uso de drogas vasoativas ( Hentschel et al., 1995; Zhang et al., 1999; Seri et al., 2002), quadros infecciosos locais ou sistêmicos (Weir et al., 1999; Hsueh et al., 2003), situações necessárias na terapêutica do recém-nascido prematuro, tais como o tipo de fototerapia (Pezzati et al., 2000), a administração da indometacina (Yanowitz et al., 1998) ou da cafeína (Hoecker et al., 2002), cateterismo de vasos umbilicais ( Rand et al., 1996; Roll e Hanssler, 1998; Shah et al., 1998).

Recém-nascidos prematuros apresentam menor resistência vascular e maior fluxo diastólico no território mesentérico que recém-nascidos de termo (Martinussen et al., 1996), devido à baixa resistência vascular geral do prematuro ou pela baixa resistência vascular seletiva devido ao crescimento rápido intestinal do recém-nascido (Nowicki e Edwards, 1992), apresentando maior quantidade local de óxido nítrico (um potente vasodilatador). A vasodilatação funcional após a alimentação enteral em recém-nascidos de termo já é bem conhecida (Van Bel et al., 1990; Coombs et al., 1992). Enquanto que o prematuro apresenta esta resposta, às vezes variável, e requer compensações hemodinâmicas sistêmicas, como o aumento do débito cardíaco, muitas vezes com redução da pressão arterial (Robel-Tilling et al., 2004). 


\subsection{Mecanismos de regulação da circulação intestinal em RN}

As características fisiológicas da circulação intestinal no recémnascido são peculiares em relação às de crianças maiores e do adulto, havendo ainda distinção entre recém-nascidos de termo e pré-termo. Esta circulação passa por mudanças dramáticas na evolução do estágio fetal para a condição neonatal e durante o primeiro mês de vida. Além disso, as respostas frente a variações das condições hemodinâmicas sistêmicas são também distintas ao do adulto. Estas mudanças visam, principalmente em preparar o intestino a assumir o papel da placenta na vida extra-uterina, no sentido de captação de nutrientes.

As características da circulação intestinal no recém-nascido são observadas tanto em relação à resistência vascular basal quanto na sua resposta frente a situações fisiológicas ou não, tais como, variação do estado hemodinâmico sistêmico, hipoxemia, estimulação adrenérgica e alimentação.

O tônus basal vascular intestinal no recém-nascido é mais baixo, caracterizando resistência vascular menor; desta forma, permite a condição de maior fluxo sanguíneo local. Estes dados são baseados em observações experimentais em que cordeiros neonatais apresentam menor resistência vascular basal intestinal, permitindo um fluxo sanguíneo local e fração de extração de oxigênio cerca de duas vezes maior que cordeiros fetais (Edelstone e Holzman, 1983). O aumento do fluxo sanguíneo intestinal no 
recém-nascido permite que o intestino mude da condição de um órgão dormente na vida intra-uterina para um órgão de intensa atividade e de crescimento, de desenvolvimento e de maturação acelerados que se estende até a adolescência.

Os mecanismos envolvidos na regulação do tônus basal do recémnascido são distintos dos de adultos. Classicamente, a regulação do tônus basal, assim como da resposta vascular em adultos ocorre através do sistema nervoso simpático e parassimpático, principalmente por meio da estimulação nervosa adrenérgica. Baseados em estudos experimentais em suínos, duas fases da regulação são descritos em recém-nascidos de termo em condições normais. Na primeira fase, no período neonatal precoce (até o primeiro e segundo mês de vida), a resistência vascular basal declina-se logo após o nascimento, atingindo um patamar estável completando a fase do lactente até cerca de seis meses (segunda fase), quando ocorre elevação até o início da adolescência, atingindo os níveis semelhantes aos do adulto. De maneira inversa, ocorre um aumento do fluxo sanguíneo basal no período neonatal precoce, mantendo-se estável na fase do lactente, quando inicia uma redução (Reber at al., 2002).

A regulação do tônus basal vascular no período neonatal precoce é determinada por um equilíbrio entre fatores constrictores e dilatadores que atuam na musculatura lisa vascular intestinal. São caracterizadas três sistemas envolvidas nesta regulação: óxido nítrico constitutivo (NO) que causa vasodilatação, resposta miogênica vascular e endotelina (ET-1), estes últimos causando vasoconstricção. O período neonatal precoce, o tônus 
vascular basal e as mudanças na resposta vascular não sofrem influência da estimulação por nervos adrenérgicos extrínsecos apesar destes estarem anatomicamente presentes nos recém-nascidos de termo ( Nowicki at al., 1991).

A regulação vascular através do NO constitutivo ocorre a partir da produção específica do NO pelas células endoteliais mediada por ação enzimática (ecNOS), seguida da difusão facilitada do NO para a musculatura lisa vascular, ativando o guanilato ciclase a produzir GMP cíclico, levando a redução do cálcio intracelular da musculatura lisa vascular, inativando o mecanismo contrátil. A produção de NO constitutivo local é contínua, podendo ser estimulada ou bloqueada por estímulos químicos ou mecânicos. Além disso, a velocidade de produção de NO é dependente da idade, sendo a fase mais acelerada do terceiro ao décimo segundo dia pósnatal (Nankervis at al., 2001; Reber at al., 2000), e ainda, a resposta de relaxamento vascular mediada por vasodilatadores NO-dependentes ( acetilcolina, bradicinina e substância $P$ ) é mais acentuada nesta fase. A dilatação induzida pelo fluxo é um mecanismo indireto da ação do NO na vasodilatação mesentérica, onde o efeito mecânico do fluxo sobre a superfície celular endotelial estimula a ação dos ecNOS ( Nowicki PT e Miller CE, 1995; Nankervis at al., 2001b). O efeito da vasodilatação mesentérica mediada pelo NO diminui ao final do primeiro mês de vida.

A resposta miogênica vascular é um mecanismo onde o aumento da pressão intravascular induz vasoconstricção; é uma resposta intrínseca da musculatura lisa vascular reflexa ao estiramento de suas fibras, sendo, 
portanto, decorrente de estímulo mecânico. O mecanismo desta resposta parece ter o envolvimento da proteína C quinase $(P K C)$ intracelular, com o aumento do influxo de cálcio para dentro das células, levando à contração das miofibrilas; bloqueadores de PKC inibem a resposta miogênica ( Davis e Hill, 1999). A resposta miogênica é mais acentuada logo após o nascimento e se declina gradativamente a final do primeiro mês de vida.

A endotelina é um peptídeo vasoativo e mitogênico produzido principalmente pelo endotélio vascular. A sua ação ocorre por duas vias: ligação em receptores de endotelina $A\left(E T_{A}\right)$ da musculatura lisa vascular levando à vasoconstricção potente e sustentada; ou, através da ligação em receptores de endotelina $\mathrm{B}\left(\mathrm{ET}_{\mathrm{B}}\right)$ levando à vasodilatação mediada por NO. A endotelina-1 apresenta suas maiores concentrações no período neonatal, efetuando a sua ação angiogênica. Em condições basais, a ação mediada pelos receptores $E T_{A}$ é mais acentuada que a ação através do $E T_{B}$ no período neonatal, permitindo a manutenção do tônus basal ( Nankervis e Nowicki, 2000; Nankervis at al., 2001A).

Ao final do primeiro mês de vida, começa a declinar os efeitos da regulação do tônus vascular mediada por NO, resposta miogênica vascular e endotelina. Neste momento, o tamanho, peso e superfície intestinal apresentaram um ganho significativo, havendo também proliferação e diferenciação vascular; desta forma, ocorre um aumento da resistência vascular devido à alteração geométrica dos vasos com aumento das ramificações. Além disso, ocorre a maturação do estímulo e da resposta ao 
estímulo da inervação adrenérgica extrínseca, também responsável pelo aumento do tônus vascular (Nankervis at al., 2001B).

\subsection{Resposta vascular da circulação intestinal em RN}

Em decorrência de sua peculiaridade na resistência vascular basal e, conseqüentemente no fluxo sanguíneo, espera-se também características específicas na resposta vascular frente à estimulação e a situações de stress. Assim, respostas de maneira à seguir, reflexa, através de quimio ou barorreceptores, eficazes são esperadas em intestinos a partir de 30 dias de vida, devido à inervação adrenérgica extrínseca.

A inervação adrenérgica é presente ao nascimento, porém o seu amadurecimento ocorre a partir do final do primeiro mês de vida. Assim, um estímulo adrenérgico no período neonatal sobre a resposta vascular intestinal, causa uma vasoconstricção tênue, evolui ao tônus basal progressivamente após alguns segundos até cerca de 2 minutos de estimulação, sendo denominado de escape autorregulatório, preservando a irrigação local (Nowicki at al., 1991).

Uma vez que o fluxo sanguíneo (Q) em um órgão alvo é diretamente proporcional à pressão de perfusão $(P)$ e inversamente proporcional à resistência vascular $(R)$ : $(Q=P / R)$; redução de pressão de perfusão até um nível fisiológico resulta em vasodilatação, para se manter a velocidade de fluxo constante, denominado de autorregulação pressão-fluxo. Esta autorregulação não é observada nos primeiros dias de vida, e se estabelece ao final do primeiro mês de vida. Como conseqüência, o intestino de recém- 
nascido nos primeiros dias de vida apresenta resposta ineficiente em manter o seu fluxo sanguíneo frente a situações de hipotensão, com redução do aporte de oxigênio (Nowicki e Miller, 1988). Este efeito pode ser justificado, pela baixa resistência vascular mesentérica nos primeiros dias de vida, fazendo com que a sua reserva de vasodilatação seja menor.

A resposta vascular intestinal frente à hipoxemia é variável dependendo do grau de hipoxemia. Em situação de hipoxemia leve ou moderada, ocorre vasodilatação; enquanto que na hipoxemia grave, a vasoconstricção com agravamento da isquemia levando à hipóxia tecidual. Esta resposta provavelmente é devido ao fato de que o oxigênio é um substrato essencial na produção do NO (Marletta, 1993).

A hiperemia pós-prandial caracteriza a resposta vasodilatadora do fluxo sanguíneo intestinal, com conseqüente aumento na liberação do oxigênio local, na presença de nutrientes na luz intestinal. Neste fenômeno, ocorre um aumento no número de capilares perfundidos, facilitando a difusão de oxigênio aos tecidos. Esta resposta é gerada por mecanismo multifatorial, depende, por vezes do nutriente presente na luz intestinal; mas a principal participação é do sistema nervoso entérico, sendo a substância $P$ intestinal, o principal neurotransmissor envolvido (Nowicki, 1998).

\subsection{Implicações das características da circulação intestinal na patogênese da enterocolite necrosante}


Quanto a enterocolite necrosante, ocorre em cerca de 75 a 90\% dos recém-nascidos prematuros, nos seus diferentes graus de apresentações e cerca de 2 a 7 \% das internações de UTIs neonatais (Reber e Nankervis, 2004). É uma doença multifatorial (Stevenson et al., 1969), sendo que quanto mais prematuro maior o risco e maior o período de risco. É também chamada de doença dos sobreviventes, pois geralmente ocorre quando o recém-nascido já superou as condições clínicas que o afligiram na fase aguda, logo ao nascimento, quando está sendo iniciada a sua alimentação. Fatores relacionados a maior risco de ocorrência de enterocolite necrosante são citados: distúrbios de fluxo sanguíneo local e sistêmico (sepse, presença de cateteres umbilicais, canal arterial patente, etc) (Bhatt et al., 2002; Kempley e Murdoch, 2003), injúria da reperfusão, presença de radicais livres, déficit enzimático (por exemplo, da enzima degradadora do fator antiplaquetário) (Ewer, 2002; Amer et al., 2004), infecção, alimentação precoce, progressão rápida da dieta, administração de fórmulas ou uso de fórmulas hipertônicas na alimentação ( Grassi et al., 2001; Carver et al., 2002; Mercier et al., 2003), infusão de drogas vasoativas ( Yanowitz et al., 1998; Zhang et al., 1999; Hoecker et al., 2002; Seri et al., 2002) dentre outros (Hsueh et al., 2003). A taxa de mortalidade devido à enterocolite necrosante é citada entre 20 a 40\%; e de complicações (cirurgias) e seqüelas de 10 a 30\% dentre os sobreviventes (Hsueh et al., 2003; Reber e Nankervis, 2004).

Histopatologicamente, observa-se a presença de necrose de coagulação, em particular nas camadas musculares intestinais. Esta 
observação provavelmente seria o evento final do processo, onde a identificação do momento e do mecanismo de isquemia se faz importante para que se possa atuar na prevenção e no controle da ocorrência da enterocolite necrosante (ECN).

No passado, a primeira teoria sobre o mecanismo de isquemia intestinal levando ao desenvolvimento da ECN foi descrita por Lloyd em 1969, onde descreve a existência de perfuração intestinal em RN com baixos índices do score de Apgar, indicando asfixia ao nascimento. Esta teoria é justificada pela presença de redistribuição de fluxo sanguíneo sistêmico com o objetivo de preservação de órgãos nobres em situações de asfixia, levando à isquemia mesentérica. Estudos experimentais vieram a confirmar esta teoria; que mais tarde, baseado em observações clínicas, foi criticada, uma vez que o principal fator predisponente da ECN seria a prematuridade e, também, porque a ECN ocorre geralmente após a primeira semana de vida, quando os efeitos da asfixia eram menos proeminentes (Kliegman e Fanaroff, 1984). Anos mais tarde, baseado no conhecimento dos mecanismos envolvidos na fisiologia da circulação intestinal no RN anteriormente descritos, seria de se esperar que a asfixia teria pequeno efeito em gerar isquemia intestinal no $\mathrm{RN}$, pois a sua resposta é via adrenérgica, além disso, o RN tem mecanismo autorregulatório de escape. Baseados nos estudos de Alward em 1978, que confirmou os achados de Lloyd, notou-se que, em seu modelo, suínos recém-nascidos nasceriam com asfixia profunda prolongada, mas antes do estudo histopatológico, é restaurado a perfusão mesentérica a partir da recuperação dos níveis 
sistêmicos da tensão de oxigênio, levando a suposição de que o dano tecidual poderia ser decorrente do mecanismo de reperfusão pós-isquemia, descrito por outros autores mais tarde (Nowicki, 1996).

Atualmente, o mecanismo de isquemia mesentérica mais aceita é decorrente de lesão endotelial, uma vez que o controle do tônus e da resposta vascular frente a estimulação decorre de fatores essencialmente citogênicas, sendo um dos fatores mais envolvidos é o óxido nítrico. A redução do aporte de oxigênio leva à redução da quantidade de NO endógeno, enquanto de a redução do fluxo diminui a resposta de produção estimulada de NO através dos ecNOS. O NO interfere no receptor transmembrana da proteína G-ligante do endotélio vascular, comprometendo a capacidade de ligação $\mathrm{K}_{\mathrm{a}}$ de inúmeras agonistas vasoconstrictoras, tais como, norepinefrina, angiotensina II e endotelina-1, que é acoplada a ação da fosfolipase C. A ativação da fosfolipase $C$ é um passo essencial para a geração de mensageiros secundários que promovem a vasoconstriç̧ão ( Paresk at al., 1996). A diminuição do NO reduz a sua ação vasodilatadora e libera os efeitos da vasoconstricção por ação mediada pela fosfolipase C; estes efeitos decorrentes da isquemia são observados em recém-nascidos no período neonatal precoce, não estando presentes após o final do primeiro mês de vida (Nowicki , 1999). Um outro mecanismo de vasoconstriç̧ão decorrente da lesão endotelial é a redução dos receptores $\mathrm{ET}_{\mathrm{B}}$ que teria uma ação acoplada aos ecNOS, aumentando a concentração de NO local ( Nankervis at al., 2001a) 
Em estudos com suínos, em situação de isquemia leve transitória (redução de cerca de $10 \%$ da tensão de oxigênio sanguíneo) seria suficiente para causar lesão endotelial, levando a vasoconstricção, mas não causaria dano direto ao epitélio intestinal. Neste modelo, observou-se a redução de NO endógeno e a isquemia é notada em recém-nascidos no terceiro dia de vida, não estando presente em $\mathrm{RN}$ ao final do primeiro mês de idade (Nowicki, 1996). Quando ocorre isquemia mais profunda e mais prolongada (redução de cerca de $50 \%$ da tensão de oxigênio por 6 horas), além da redução do NO, ocorre também um aumento da produção local de endotelina-1, que aliado a redução dos receptores $\mathrm{ET}_{\mathrm{B}}$, exerce maior ação vasoconstrictora (Nowicki, 1996). A existência de maior concentração de ET1 pós-isquemia é o que mantém a situação de resistência vascular aumentada prolongada, mesmo após o re-estabelecimento das causas da isquemia (Nankervis at al., 2001a).

Outros fatores são também citados na lesão endotelial, contribuindo para o processo de isquemia: a presença do fator de ativação plaquetária (PAF), um lipídio mediador da inflamação potente (Caplan at al., 1990); a ocorrência da translocação bacteriana, com a liberação de toxinas próprias ou inflamatórias; e a própria diminuição do trânsito intestinal, levando a fermentação de açúcares na luz intestinal e a produção de ácido graxos de cadeia curta causando destruição da mucosa intestinal, fazendo com que a microvasculatura tenha contato direto com substâncias tóxicas ( Reber at al., 2002).

As hipóteses acima descritas se sustentam como mecanismos 
patogênicos da NEC baseados em constatações clínicas e histopatológicas, onde em fase inicial da doença, observa-se ilhotas de isquemia e necrose na mucosa intestinal (Tait e Kealy, 1984) antes de se apresentar como uma lesão extensa em toda a parede e em toda a extensão dos intestinos, o que seria esperado em caso de obstrução ou interrupção de fluxo sanguíneo em algum vaso de irrigação; além disso, modelos experimentais com indução da atividade do PAF produzem lesões intestinais semelhantes a ECN (Caplan at al., 1990). Devido às peculiaridades da circulação sanguínea intestinal no período neonatal, pode-se entender como a ECN é uma doença específica desta faixa de pacientes. Por outro lado, por se tratar de uma doença multifatorial, outros estudos são necessários, para se determinar fatores etiopatogênicos, principalmente em RN que não apresentam risco evidente ao desenvolvimento desta doença.

\subsection{Dopplerfluxometria da artéria mesentérica superior}

O estudo de territórios vasculares, caracterizando a irrigação de determinados órgãos alvos, pode ser realizado através de um método não invasivo de imagem, utilizando-se o ultrassom com Doppler colorido ( Kenneth e Taylor, 1985; Kenneth e Taylor, 1990; Bude et al., 1999; DeCobelli et al., 2001) . Este tipo de estudo pode ser realizado desde a vida intra-uterina, inicialmente descrito por Fitzgerald e Drumm em 1977 (Bhatt et al., 2002; Robel-Tilling, 2002). Os principais territórios vasculares estudados após o nascimento são: cerebral média, aorta, renal, celíaco e mesentérico 
superior (Evans et al., 2002; Kluckow e Evans, 2002)). Alterações do fluxo mesentérico superior e das respostas deste fluxo frente a algumas condições específicas estão relacionadas à evolução do recém-nascido, particularmente no que diz respeito à progressão da alimentação e ao desenvolvimento de quadros de intolerância até de enterocolite necrosante (Lane et al., 1998; Pezzati et al., 2000; Pezzati, et al., 2004).

O fluxo sanguíneo mesentérico apresenta algumas respostas já conhecidas frente a situações a que o recém-nascido é exposto após o nascimento, tais como, vasodilatação no período após alimentação, diferentes respostas diante da administração de drogas vasoativas, na sepse e na fototerapia. Estas respostas são já descritas em recém-nascidos de termo; enquanto que no prematuro, resposta semelhante é esperada (Fang et al., 2001), porém não são conhecidas as características desta resposta ou se pode ser quantificada dependendo da idade gestacional.

Desta forma, este estudo se justifica pela necessidade de se conhecer as características e a resposta do fluxo sanguíneo mesentérico em recém-nascidos prematuros, correlacionando a sua maturação com a idade pós-conceptual ou pós-natal e identificar estas características frente a situações específicas dos recém-nascidos, às vezes, considerados como agravos ao seu estado de saúde, tais como, estados hipermetabólicos, infecções, repercussões da persistência do canal arterial, uso de drogas vasoativas, fototerapia, ventilação mecânica agressiva, dentre outros; na tentativa de estabelecer o estudo da dopperfluxometria mesentérica como um método preditivo que possa acompanhar a evolução do recém-nascido 
prematuro, particularmente com relação a uma progressão segura da sua alimentação, reduzindo os riscos deste em desenvolver quadros gastrointestinais com o comprometimento de sua vitalidade.

\subsection{Hipótese}

Tendo em vista que o recém-nascido prematuro nasce numa condição de desenvolvimento e maturação tecidual, em particular, no território vascular da artéria mesentérica superior, de acordo com a idade gestacional de nascimento e esta condição de imaturidade pode ser determinante da sua susceptibilidade a doenças específicas do período neonatal; a possibilidade de detecção dos parâmetros de fluxo sanguíneo neste território e da resposta deste fluxo diante da condição fisiológica da alimentação enteral, através da dopplerfluxometria, torna possível a caracterização da evolução dos parâmetros das medidas de fluxo sanguíneo da artéria mesentérica superior de acordo com a idade gestacional.

A nossa hipótese foi a de que as características das medidas de fluxo sanguíneo da artéria mesentérica superior, através da dopplerfluxometria, em recém-nascidos prematuros, apresentam uma evolução peculiar decorrente do seu estágio de desenvolvimento e maturação vascular neste território. 
2. Objetivos 


\section{OBJETIVOS}

\section{Objetivo principal:}

- Descrever, através da dopplerfluxometria, as características do fluxo sanguíneo da artéria mesentérica superior e das mudanças destes parâmetros de acordo com a evolução da idade gestacional pós-natal, em recém-nascidos prematuros saudáveis de idade gestacional menor ou igual a 34 semanas completas e maiores de 27 semanas de idade gestacional ao nascimento.

\section{Objetivo secundário:}

- Descrever as mudanças dos parâmetros da dopplerfluxometria em recém-nascidos prematuros saudáveis de idade gestacional menor ou igual a 34 semanas completas e maiores de 27 semanas de idade gestacional frente à condição fisiológica da alimentação enteral e de acordo com a evolução da idade gestacional pós-natal. 
3. Material e métodos 


\section{MATERIAL E MÉTODOS}

Trata-se de um estudo de coorte realizado no Serviço de Neonatologia do Hospital e Maternidade São Luiz (São Paulo, Brasil), no período de junho de 2005 a dezembro de 2006, tendo sido aprovado pelo Comitê de Ética em Pesquisa (protocolo no 084/2005 - CAAE 0005.0.220.015-05) em 28 de abril de 2005; e a ciência da Comissão de Ética para Análise de Projetos de Pesquisa (CAPPesq) da Diretoria Clínica do Hospital das Clínicas e da Faculdade de Medicina da Universidade de São Paulo em 13 de novembro de 2006 (Protocolo de Pesquisa no 1131/06). Os recém-nascidos somente foram incluídos na pesquisa após o termo de consentimento livre e esclarecido ser assinado pelos pais ou responsáveis legais.

\subsection{Grupos de estudo}

Foram incluídos recém-nascidos pré-termo saudáveis adequados para a idade gestacional, de idades gestacionais entre 27 e 34 semanas completas, sendo agrupados em cada faixa de idade gestacional da semana completa.

Foram adotados como critérios de exclusão: recém-nascidos em condição de instabilidade hemodinâmica; necessitando de ventilação assistida com índice de oxigenação maior que 0,5; grandes mal-formações 
ou síndromes clínicas; intolerância alimentar ou enterocolite necrosante diagnosticada por quadro clínico compatível e radiografia abdominal sugestiva; situações que alterassem o fluxo sanguíneo mesentérico, tais como: asfixia perinatal, fototerapia, presença de cateteres umbilicais, persistência de canal arterial; pequenos para a idade gestacional, uso de drogas vasoativas e recém-nascidos de mães com hipertensão arterial, trombofilias, infecções, além da restrição de crescimento intra-uterino.

\subsection{Dopplerfluxometria}

\subsubsection{Efeito Doppler}

O efeito Doppler utilizado para medidas de fluxo, baseia-se em um princípio físico descrito pelo matemático e físico Christian Doppler, em 1842, a partir da observação da variação das cores refletidas pelas estrelas celestes, publicado em "Über das farbige Licht der Doppelsterne und einiger anderer Gestirne des Himmels" (Doppler apud Marsal et al, 1998), que significa: Sobre as luzes coloridas das estrelas binárias e outras estrelas.

Este princípio físico é válido para todos os tipos de propagação de ondas, sendo a mudança observada na freqüência de uma onda quando esta é refletida por um objeto em movimento; esta mudança é tanto maior quanto maior a velocidade do objeto em movimento.

Este princípio é utilizado na medicina para o estudo de fluxos, principalmente para estudo de velocidade de fluxo sanguíneo. Os 
equipamentos desenvolvidos para este propósito possuem transdutores de cristais piezoelétricos que atuam como fonte emissora de feixes sonoros e receptores dos ecos emitidos. Ocorre uma mudança da freqüência da onda refletida em relação à onda sonora emitida, quando esta atinge uma coluna de fluxo em movimento, por exemplo, a corrente sanguínea. E esta diferença de freqüência sonora é diretamente proporcional à velocidade do fluxo sanguíneo, sendo convertida em sinal elétrico; que após processamento, os sinais elétricos são apresentados em forma de som, ou graficamente, por meio de sonograma exibido em tela de vídeo (Kenneth e Taylor, 1990; Zugaib, 2000).

\subsubsection{Tipos de Doppler}

Os aparelhos de Doppler podem ser classificados como de onda contínua ou de onda pulsátil, de acordo com a forma de emissão das ondas ultra-sônicas.

Os aparelhos de onda contínua possuem dois cristais piezoelétricos, um para a emissão de ondas e o outro para a recepção, de funcionamento contínuo e geralmente são de baixo custo e portáteis. Assim, todos os sinais refletidos por estruturas em movimento ao longo do trajeto do feixe de onda são registrados; como conseqüência, a resultante final pode ser uma somatória dos sinais refletidos por mais de um vaso. Enquanto que, aparelhos de onda pulsátil possuem apenas um cristal piezoelétrico com 
funcionamento intermitente, ou emitindo ou refletindo ondas sonoras; como resultados, os sinais são processados em uma "janela" a partir de ecos refletidos por uma região bem delimitada.

A utilização de Doppler isoladamente, ou seja, não acoplada a um sistema de ultra-som bidimensional convencional, pode ser denominada se forma "cega", uma vez que o exame é orientado apenas por meio de sinais acústicos, sendo não discriminatórios, por não permitir a identificação da estrutura específica ou a posição do sistema em relação à onda emissora. Da mesma maneira, o uso de Doppler isoladamente não permite a reprodutibilidade dos exames, uma vez que é pouco provável que se localize a mesma região estudada apenas baseando-se em características acústicas.

Assim, avanços tecnológicos produziram equipamentos que integram os sistemas de onda pulsátil ao do ultra-som bidimensional convencional, chamados de sistemas "duplex scan". A partir disso, tornou-se possível a seleção do vaso, ou da porção específica deste, identificando-o a partir da imagem ecográfica convencional, aplicando-se posteriormente o estudo pelo Doppler. Este sistema permite definir a posição e a profundidade do vaso a ser estudado, além disso, o diâmetro da janela do Doppler pode ser variado de acordo com as dimensões do vaso, tornando a leitura dos sinais do fluxo bastante fidedignos. O processamento dos sinais sonográficos por aparelhos que possuem este sistema, representa não apenas em forma acústica, como em forma gráfica, permitindo a análise da velocidade do fluxo sanguíneo 
correlacionando com o ciclo cardíaco (Kenneth e Taylor, 1985; Kenneth e Taylor, 1990).

Além do sistema "duplex scan", o Doppler pulsátil pode também ser colorido, onde o sonograma é substituído por um mapa colorido sobreposto à imagem ultra-sonográfica bidimensional, cujas cores variam de acordo com, não apenas a velocidade, mas também, ao sentido do fluxo sanguíneo. Este recurso permite a avaliação mais apurada de vasos de pequeno calibre.

\subsubsection{Interpretação dos resultados dopplervelocimétricos}

A interpretação dos sonogramas pode ser qualitativa ou quantitativa. A análise qualitativa baseia-se na sua morfologia, onde a presença de pico elevado de fluxo na diástole arterial caracteriza territórios de baixa resistência vascular; e a rapidez na "queda" da onda entre o pico máximo na sístole e o pico diastólico final, fazendo com que a área sob a linha da onda seja reduzida, representando baixo preenchimento vascular arterial.

Alguns aspectos técnicos inerentes ao próprio método dopplervelocimétrico, tais como, a dificuldade de obtenção de ângulo de insonação adequado e a imprecisão nas medidas da secção transversa dos vasos tornam o exame inadequado como medida direta dos valores de velocidade ou de volume de fluxo sanguíneo.

Deste modo, a análise dos sonogramas é feita através de índices que expressam a impedância ao fluxo distalmente ao ponto examinado. Tais 
índices estabalecem relações entre os valores de velocidade na sístole, na diástole e a média das velocidades de um ciclo cardíaco, eliminando os erros citados acima.

Os principais índices utilizados são:

- $\quad$ índice de resistência (Pourcelot, 1974): relação da diferença entre as velocidade sistólica máxima e a velocidade diastólica mínima, sobre a velocidade sistólica máxima;

índice de pulsatilidade: relação da diferença entre a velocidade sistólica máxima e a velocidade diastólica mínima, sobre a velocidade média da onda. No caso de território venoso, a variante deste índice é a relação da diferença entre a velocidade de pico na sístole ventricular e a velocidade mínima na contração atrial, sobre a velocidade média da onda (Gosling e King, 1975);

relação sístole/diástole: relação entre a velocidade sistólica máxima e a velocidade diastólica mínima (Stuart et al, 1980). Além dos índices descritos, estabelecem-se as medidas quantitativas de fluxo sanguíneo por meio dos picos de velocidades: sistólica e diastólica final. 
Neste trabalho, o exame dopplerfluxométrico foi obtido por meio do aparelho Logiq Book 8C-RS (General Eletric - EUA), por meio de uma sonda setorial de $8 \mathrm{MHz}$, sendo as medidas de Doppler colorido pulsado obtidas por ondas sonográficas de $4 \mathrm{MHz}$.

O recém-nascido foi mantido em posição supina, o transdutor foi posicionado em região epigástrica logo abaixo do apêndice xifóide, obtendose as imagens bidimencionais do tronco celíaco e da artéria mesentérica superior alguns milímetros após a sua emergência da aorta em plano sagital.

As medidas de fluxo foram obtidas no sentido longitudinal do vaso e ângulo de insonação de 0 a 20 graus, não necessitando de fator de correção; caso por dificuldades técnicas de melhor posicionamento da imagem do vaso, o ângulo de até 20 graus não for obtido; o aparelho utilizado neste estudo possui um sistema de correção automático, permitindo a medida correta dos índices de resistência. As curvas de fluxo sanguíneo foram registradas após uma seqüência de cinco medidas estáveis, tanto em relação à qualidade de onda, quanto do aspecto audível da mesma (Coombs et al, 1992; DeCobelli et al, 2001; Leidig E, 1989). As imagens e as medidas foram gravadas para posterior confirmação caso necessário, como medida de segurança.

As medidas obtidas foram: pico de velocidade sistólica, pico de velocidade diastólica final e média de velocidade de fluxo; sendo, após, calculado o índice de Pourcelot, conforme a fórmula: [pico de velocidade sistólico - pico diastólico final] / pico de velocidade sistólico, que representa um índice de resistência e também foi aferido o índice de pulsatilidade, 
calculado pela razão entre a diferença da velocidade sistólica máxima e da diastólica mínima e a velocidade média da onda (figura 1).

Os exames foram realizados antes da alimentação (até 30 minutos) e após a alimentação (entre 15 e 60 minutos). No caso do neonato estar em jejum, apenas uma medida foi obtida para avaliação do estado basal momentâneo do fluxo sanguíneo da artéria mesentérica superior.

As avaliações foram realizadas no primeiro dia (entre 6 a 24 horas de vida), no $3^{\circ}$ dia e no sétimo dias e seqüencialmente, a cada 7 dias até 6 semanas de vida ou até completar 34 semanas de idade gestacional pósconceptual em nutrição enteral plena ou até completar 40 semanas de idade gestacional pós-conceptual.

Durante a realização dos exames, foram coletados dados de condições hemodinâmicas: freqüência cardíaca, pressão arterial, freqüência respiratória, quantificação da diurese, parâmetros ventilatórios, oferta hídrica e volume de dieta.

Os valores obtidos foram expressos em médias e desvios padrão. As medidas foram realizadas por três observadores qualificados e experientes, respeitando a mesma técnica.

Inicialmente, os resultados foram agrupados de duas maneiras: de acordo com a idade gestacional pós-conceptual que o RN se encontra e de acordo com a idade gestacional pós-natal no momento do exame; para posterior análise descritiva. 
Figura 1- Imagem ultra-sonográfica bidimensional da região da artéria mesentérica superior em recém-nascido pré-termo no $7^{\circ}$ dia de vida

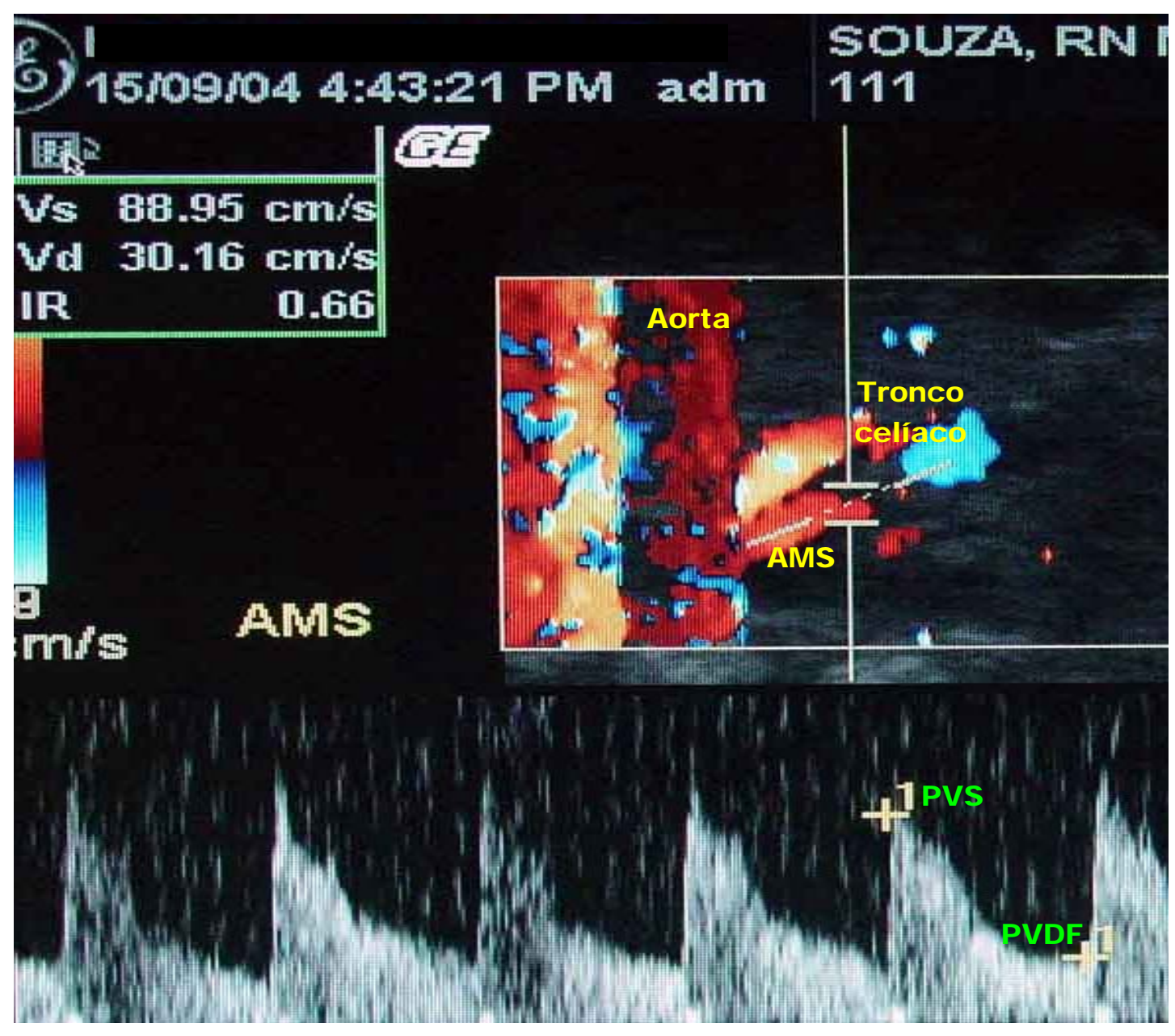




\subsection{Desenho do estudo}

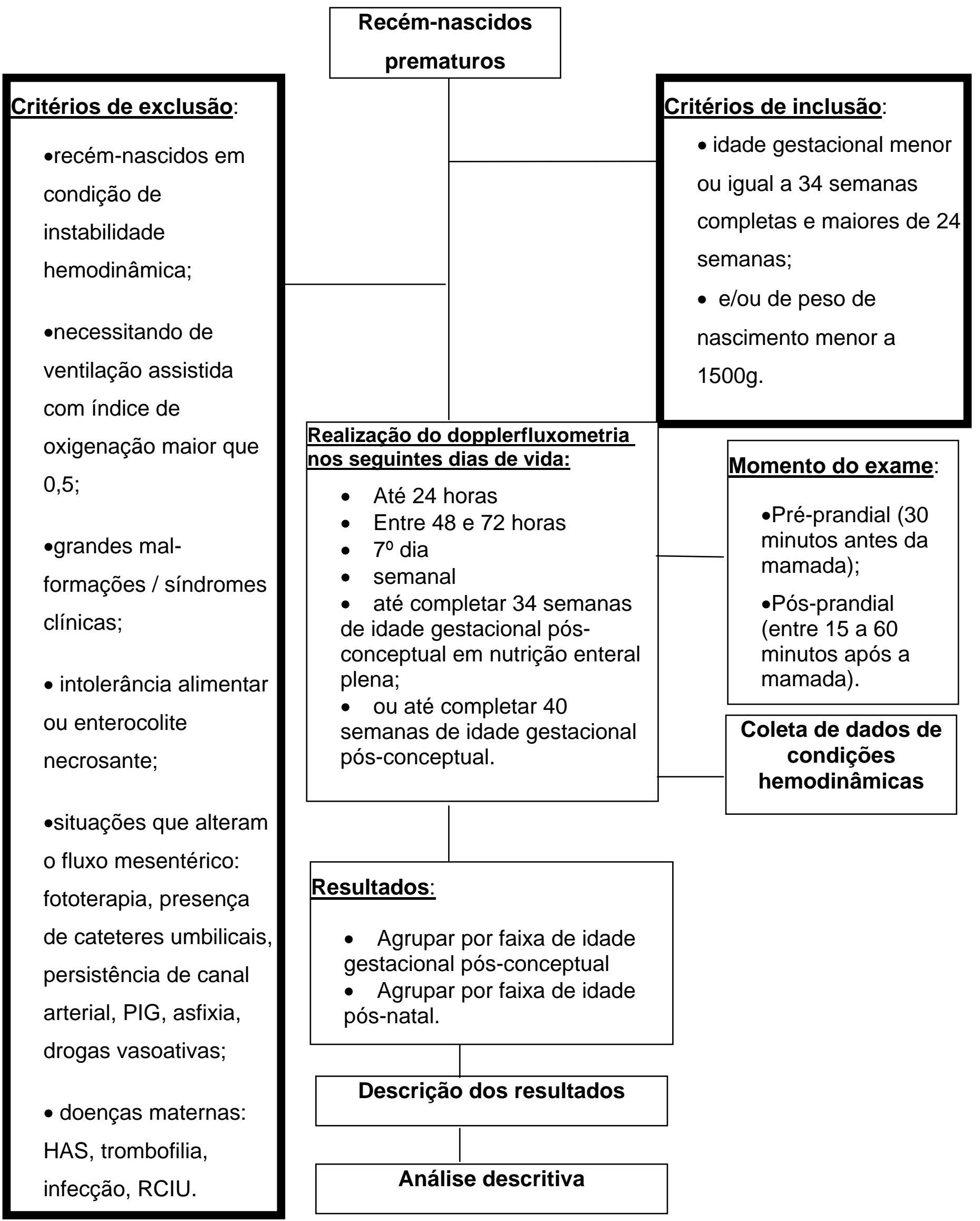


4. Resultados 


\section{RESULTADOS}

\subsection{Descrição e caracterização dos grupos de estudo}

Ao total, foram estudados 77 recém-nascidos pré-termo adequados para a idade gestacional, sendo 43 do sexo feminino e 34 do sexo masculino e cujas características de peso e de idade gestacional ao nascimento são representados na tabela 1 . Sendo totalizados 125 exames, distribuídos nos dias de vida, sendo 12 exames do primeiro dia, 6 do terceiro, 20 do sétimo, 34 do $14^{\circ}$ dia, 20 do $21^{\circ}$ dia, 16 do $28^{\circ}$ dia, 9 do $35^{\circ}$ dia e 8 da sexta semana de vida.

Tabela 1- Caracterização da população do estudo quanto à idade gestacional e peso de nascimento ( $\mathrm{n}$ total=77)

\begin{tabular}{cccccccc}
$\begin{array}{c}\text { Idade } \\
\text { gestacional } \\
\text { (semanas) }\end{array}$ & $\begin{array}{c}27 \\
\mathrm{a} 27^{6}\end{array}$ & $\begin{array}{c}28 \\
\mathrm{a} 28^{6}\end{array}$ & $\begin{array}{c}29 \\
\mathrm{a} 29^{6}\end{array}$ & $\begin{array}{c}30 \\
\mathrm{a} 30^{6}\end{array}$ & $\begin{array}{c}31 \\
\mathrm{a} 31^{6}\end{array}$ & $\begin{array}{c}32 \\
\mathrm{a} 32^{6}\end{array}$ & $\begin{array}{c}33 \\
\mathrm{a} 34\end{array}$ \\
\hline \hline $\begin{array}{c}\text { Peso (g) } \\
\text { (média } \pm \mathrm{dp})\end{array}$ & $\begin{array}{c} \pm 83 \\
\pm\end{array}$ & $\begin{array}{c}1170 \\
\pm\end{array}$ & $\begin{array}{c}1296 \\
\pm\end{array}$ & $\begin{array}{c}1620 \\
\pm\end{array}$ & $\begin{array}{c}1975 \\
\pm\end{array}$ & $\begin{array}{c}2170 \\
\pm\end{array}$ & $\begin{array}{c}2390 \\
\pm\end{array}$ \\
$\mathrm{n}$ & 214 & 320 & 341 & 289 & 271 & 116 \\
\hline
\end{tabular}


A tabela 2 representa os parâmetros das condições hemodinâmicas dos recém-nascidos a cada momento que o exame foi realizado. Os dados da tabela 2 atestam que esses neonatos possuíam condições clínicas e hemodinâmicas saudáveis e estáveis sistemicamente, baseados na freqüência cardíaca, pressão arterial média, freqüência respiratória, fluxo urinário, oferta hídrica total, além da presença da boa tolerância da dieta a partir da sua introdução.

Tabela 2- Caracterização da população do estudo quanto às condições clínicas, hemodinâmicas, fluxo urinário e oferta hídrica $(n=77)$

\begin{tabular}{|c|c|c|c|c|c|c|c|c|}
\hline & $1^{\circ} \mathrm{dia}$ & $3^{\circ} \mathrm{dia}$ & $7^{\circ} \mathrm{dia}$ & $14^{\circ} \mathrm{dia}$ & $21^{\circ} \mathrm{dia}$ & $28^{\circ} \mathrm{dia}$ & $35^{\circ} \mathrm{dia}$ & $42^{\circ}$ dia \\
\hline FC & $\begin{array}{r}132,9 \\
\pm 12,5\end{array}$ & $\begin{array}{l}146,5 \\
\pm 5,8\end{array}$ & $\begin{array}{l}130,5 \\
\pm 5,8\end{array}$ & $\begin{array}{c}128,0 \pm \\
6,0\end{array}$ & $134,0 \pm 4,1$ & $124,1 \pm 7,1$ & $\begin{array}{c}122,2 \pm \\
6,7\end{array}$ & $\begin{array}{c}128,3 \pm \\
2,1\end{array}$ \\
\hline PAM & $\begin{array}{c}34,5 \pm \\
2,3\end{array}$ & $\begin{array}{c}30,4 \pm \\
4,2\end{array}$ & $\begin{array}{c}36,4 \pm \\
3,2\end{array}$ & $\begin{array}{c}35,8 \pm \\
5,6\end{array}$ & $38,2 \pm 7,1$ & $42,3 \pm 4,9$ & $\begin{array}{c}49,8 \pm \\
4,7\end{array}$ & $\begin{array}{c}47,8 \pm \\
5,2\end{array}$ \\
\hline FR & $\begin{array}{c}53,1 \pm \\
7,1\end{array}$ & $\begin{array}{c}55,3 \pm \\
3,8\end{array}$ & $\begin{array}{c}45,3 \pm \\
3,8\end{array}$ & $\begin{array}{c}41,2 \pm \\
4,6\end{array}$ & $40,0 \pm 8,2$ & $36,8 \pm 6,4$ & $\begin{array}{c}34,6 \pm \\
7,8\end{array}$ & $\begin{array}{c}38,2 \pm \\
6,9\end{array}$ \\
\hline $\begin{array}{c}\text { Fluxo } \\
\text { urinário }\end{array}$ & $\begin{array}{c}1,8 \pm \\
0,8\end{array}$ & $\begin{array}{c}2,2 \pm \\
1,2\end{array}$ & $\begin{array}{c}2,8 \pm \\
0,8\end{array}$ & $\begin{array}{c}3,2 \pm \\
1,5\end{array}$ & $4,2 \pm 1,6$ & $4,1 \pm 1,8$ & $\begin{array}{c}4,8 \pm \\
1,2\end{array}$ & $\begin{array}{c}4,6 \pm \\
1,7\end{array}$ \\
\hline $\begin{array}{l}\text { Oferta } \\
\text { hídrica }\end{array}$ & $\begin{array}{c}80,0 \pm \\
6,5\end{array}$ & $\begin{array}{c}85,3 \pm \\
8,9\end{array}$ & $\begin{array}{c}105,3 \pm \\
12,5\end{array}$ & $\begin{array}{c}134,2 \pm \\
25,4\end{array}$ & $\begin{array}{c}147,8 \pm 18 \\
9\end{array}$ & $\begin{array}{c}167,9 \pm 15 \\
7\end{array}$ & $\begin{array}{c}169,4 \pm \\
21,9\end{array}$ & $\begin{array}{c}172,6 \pm \\
17,2\end{array}$ \\
\hline
\end{tabular}

FC: freqüência cardíaca em batimentos por minuto (média \pm desvio padrão)

PAM: pressão arterial média em mmHg (média \pm desvio padrão)

FR: freqüência respiratória em respirações por minuto (média \pm desvio padrão)

Fluxo urinário em $\mathrm{ml} / \mathrm{kg} /$ minuto (média \pm desvio padrão)

Oferta hídrica em ml/kg (média \pm desvio padrão) 


\subsection{Resultados da dopplerfluxometria}

A tabela 3 representa os valores médios e seus respectivos desvios padrão dos índices que representam resistência vascular: índice de resistência (IR) e índice de pulsatilidade (IP) pré e pós prandiais. Os valores de índices de resistência mostram uma tendência à diminuição no terceiro dia de vida, elevando-se a seguir, mantendo-se estável até a quarta semana de vida; a partir de então, mostra uma ligeira elevação no decorrer de duas semanas seqüenciais. Quanto às medidas pós prandiais, nota-se uma tendência à elevação no terceiro dia de vida, estabilizando a partir do sétimo dia até o final do primeiro mês, quando mostra elevação nas duas semanas a seguir; porém, em todo o período estudado, o índice de resistência parece não se modificar com a alimentação, na mesma idade de comparação, exceto no terceiro dia de vida (tabela 3 , gráfico 1 ). 
Tabela 3- Índices de resistência e de pulsatilidade no $1^{\circ}, 3^{\circ}, 7^{\circ}, 14^{\circ}, 21^{\circ}, 28^{\circ}$, $35^{\circ}, 42^{\circ}$ dias de vida, nos momentos pré e pós prandiais (valores em médias e desvios padrão)

\begin{tabular}{|c|c|c|c|c|}
\hline Dias de vida & & & & \\
\hline & $\begin{array}{c}\text { Pré } \\
\text { prandial }\end{array}$ & $\begin{array}{c}\text { Pós } \\
\text { prandial }\end{array}$ & $\begin{array}{c}\text { Pré } \\
\text { prandial }\end{array}$ & $\begin{array}{c}\text { Pós } \\
\text { prandial }\end{array}$ \\
\hline $1^{0}$ & $0,69 \pm 0,09$ & $0,66 \pm 0,10$ & $1,45 \pm 0,30$ & $1,38 \pm 0,39$ \\
\hline $3^{\circ}$ & $0,67 \pm 0,15$ & $0,70 \pm 0,21$ & $1,35 \pm 0,28$ & $1,40 \pm 0,29$ \\
\hline $7^{\circ}$ & $0,75 \pm 0,07$ & $0,74 \pm 0,07$ & $1,68 \pm 0,29$ & $1,58 \pm 0,26$ \\
\hline $14^{\circ}$ & $0,74 \pm 0,07$ & $0,73 \pm 0,08$ & $1,50 \pm 0,23$ & $1,46 \pm 0,26$ \\
\hline $21^{\circ}$ & $0,75 \pm 0,07$ & $0,75 \pm 0,06$ & $1,47 \pm 0,22$ & $1,45 \pm 0,24$ \\
\hline $28^{\circ}$ & $0,76 \pm 0,07$ & $0,76 \pm 0,06$ & $1,52 \pm 0,20$ & $1,50 \pm 0,27$ \\
\hline $35^{\circ}$ & $0,79 \pm 0,03$ & $0,77 \pm 0,04$ & $1,62 \pm 0,09$ & $1,58 \pm 0,10$ \\
\hline $42^{\circ}$ & $0,78 \pm 0,05$ & $0,77 \pm 0,03$ & $1,68 \pm 0,06$ & $1,64 \pm 0,04$ \\
\hline
\end{tabular}

IR=Índice de Resistência 
Gráfico 1- Valores médios dos índices de resistência (IR) pré e pósprandiais, nas primeiras seis semanas de vida

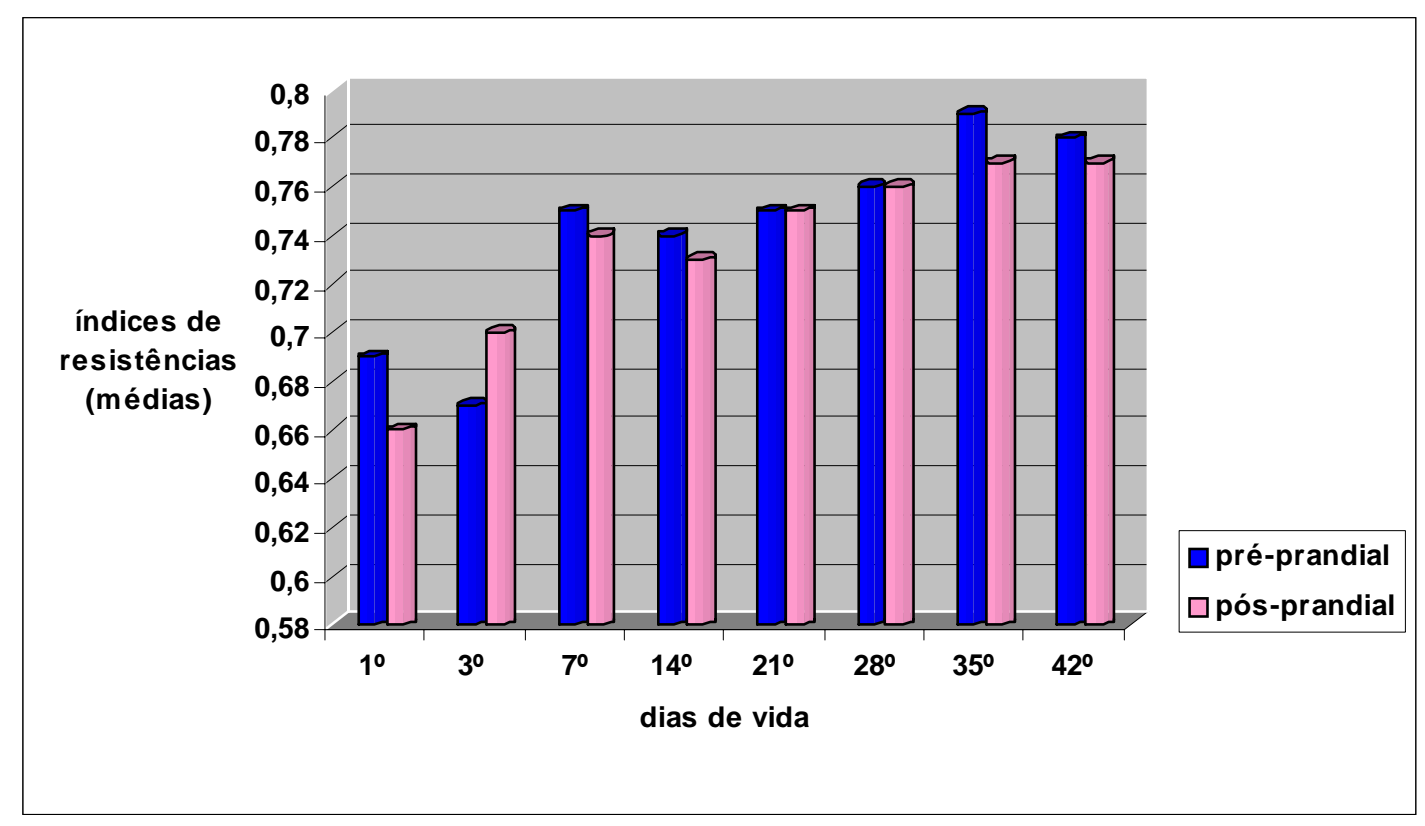

Gráfico 2- Valores médios dos índices de pulsatilidade (IP) pré e pósprandiais, nas primeiras seis semanas de vida

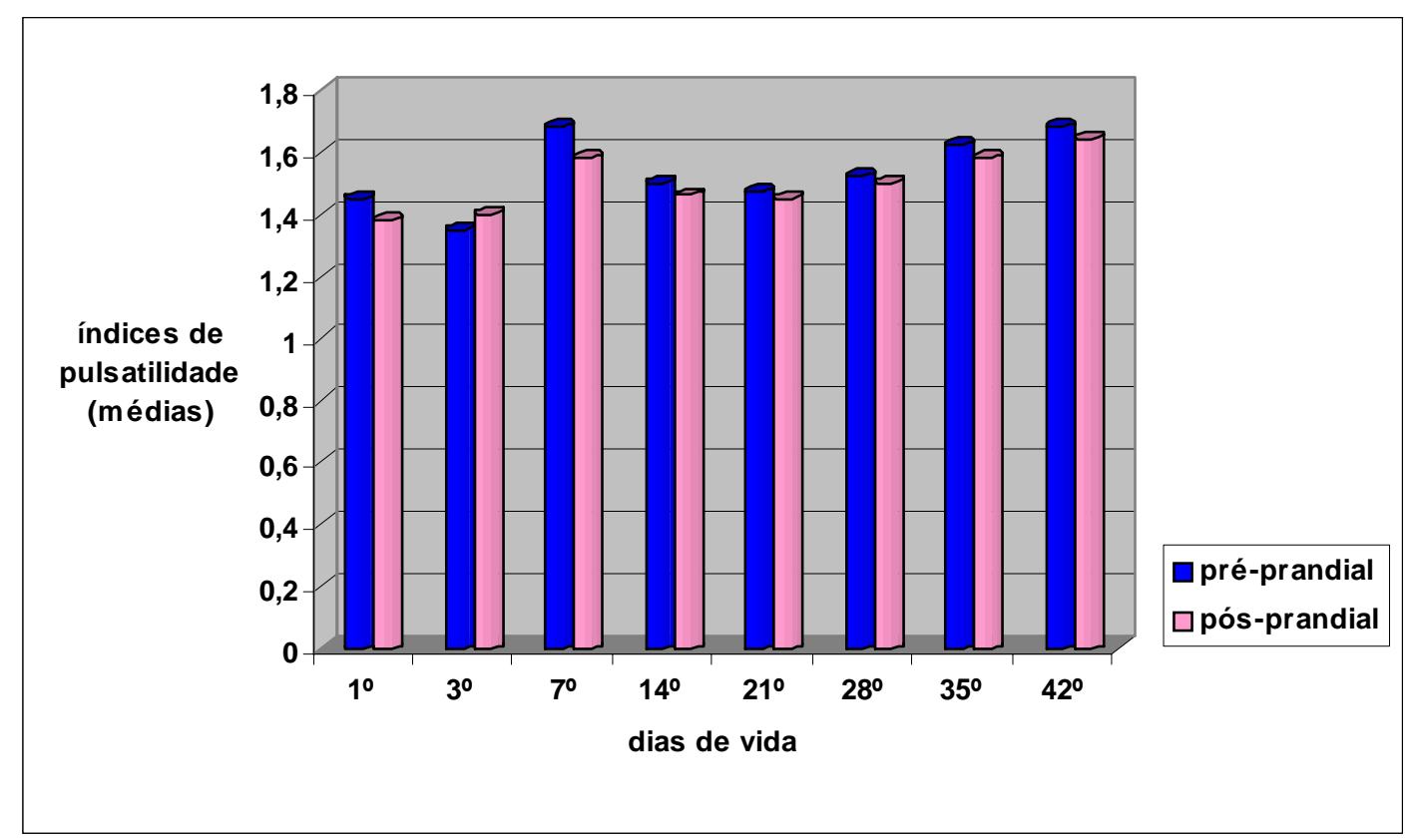


Quanto aos valores do índice de pulsatilidade (IP), assim como o índice de resistência, o IP tende a diminuir no terceiro dia de vida, elevandose no sétimo e mantendo-se estável até o final da quarta semana de vida, quando aumenta novamente nas duas próximas semanas (tabela 3, gráfico 2). Da mesma forma, as medidas pós prandiais do IP diminuem no primeiro dia, ascendem no terceiro dia, estabilizam-se a partir do sétimo até o final do primeiro mês quando voltam a elevar-se até a sexta semana de vida. Porém, à semelhança do IR, parece não se modificarem com a alimentação, exceto no terceiro dia de vida.

Os resultados de índices de resistência vascular (IR e IP) mostram que esses recém-nascidos pré-termo apresentam uma resposta vascular mesentérica à alimentação distinta no terceiro dia de vida.

A seguir, os resultados que demonstram quantidade de fluxo sanguíneo, medidas pelos picos de velocidades sistólica e diastólica final nos períodos pré e pós prandiais são representados na tabela 4 . O fluxo sanguíneo mesentérico reduz-se no terceiro dia de vida, recuperando-se no sétimo, de maneira estável até 28 dias, quando mostra uma nova redução nas duas semanas seguintes. Porém, a resposta vasodilatadora à alimentação pode ser notada desde os primeiros dias de vida, de maneira ascendente até o final do primeiro mês, a partir do qual, mostra uma ligeira redução nas duas semanas a seguir (tabela 3, gráficos 3 e 4). 
Tabela 4- Picos de velocidades sistólica e diastólica final no $1^{\circ}, 3^{\circ}, 7^{\circ}, 14^{\circ}$, $21^{\circ}, 28^{\circ}, 35^{\circ}, 42^{\circ}$ dias de vida, nos momentos pré e pós prandiais (valores em médias e desvios padrão)

\begin{tabular}{|c|c|c|c|c|}
\hline \multirow{3}{*}{$\begin{array}{c}\text { Dias de } \\
\text { vida }\end{array}$} & \multicolumn{2}{|c|}{ PVS (cm/s) } & \multicolumn{2}{|c|}{ PVDF (cm/s) } \\
\hline & Pré & Pós & Pré & Pós \\
\hline & prandial & prandial & prandial & prandial \\
\hline $1^{\circ}$ & $60,51 \pm 22,24$ & $59,62 \pm 24,14$ & $18,85 \pm 6,09$ & $20,63 \pm 6,89$ \\
\hline $3^{\circ}$ & $55,24 \pm 26,04$ & $110,82 \pm 32,45$ & $18,66 \pm 10,01$ & $30,15 \pm 12,78$ \\
\hline $7^{\circ}$ & $90,61 \pm 12,74$ & $118,10 \pm 20,15$ & $20,99 \pm 8,12$ & $27,98 \pm 9,72$ \\
\hline $14^{\circ}$ & $95,33 \pm 18,11$ & $121,95 \pm 24,18$ & $22,02 \pm 8,50$ & $29,02 \pm 10,05$ \\
\hline $21^{\circ}$ & $92,89 \pm 15,40$ & $124,15 \pm 25,16$ & $23,04 \pm 7,89$ & $34,56 \pm 9,00$ \\
\hline $28^{\circ}$ & $96,96 \pm 12,18$ & $126,07 \pm 18,17$ & $22,24 \pm 8,02$ & $32,02 \pm 8,45$ \\
\hline $35^{\circ}$ & $63,18 \pm 14,08$ & $96,68 \pm 11,12$ & $11,99 \pm 6,15$ & $19,02 \pm 4,95$ \\
\hline $42^{\circ}$ & $58,12 \pm 9,78$ & $96,12 \pm 8,98$ & $12,05 \pm 5,12$ & $21,15 \pm 3,43$ \\
\hline
\end{tabular}


Gráfico 3- Médias de picos de velocidades sistólica (PVS) pré e pósprandiais, nas primeiras seis semanas de vida em $\mathrm{cm} / \mathrm{s}$

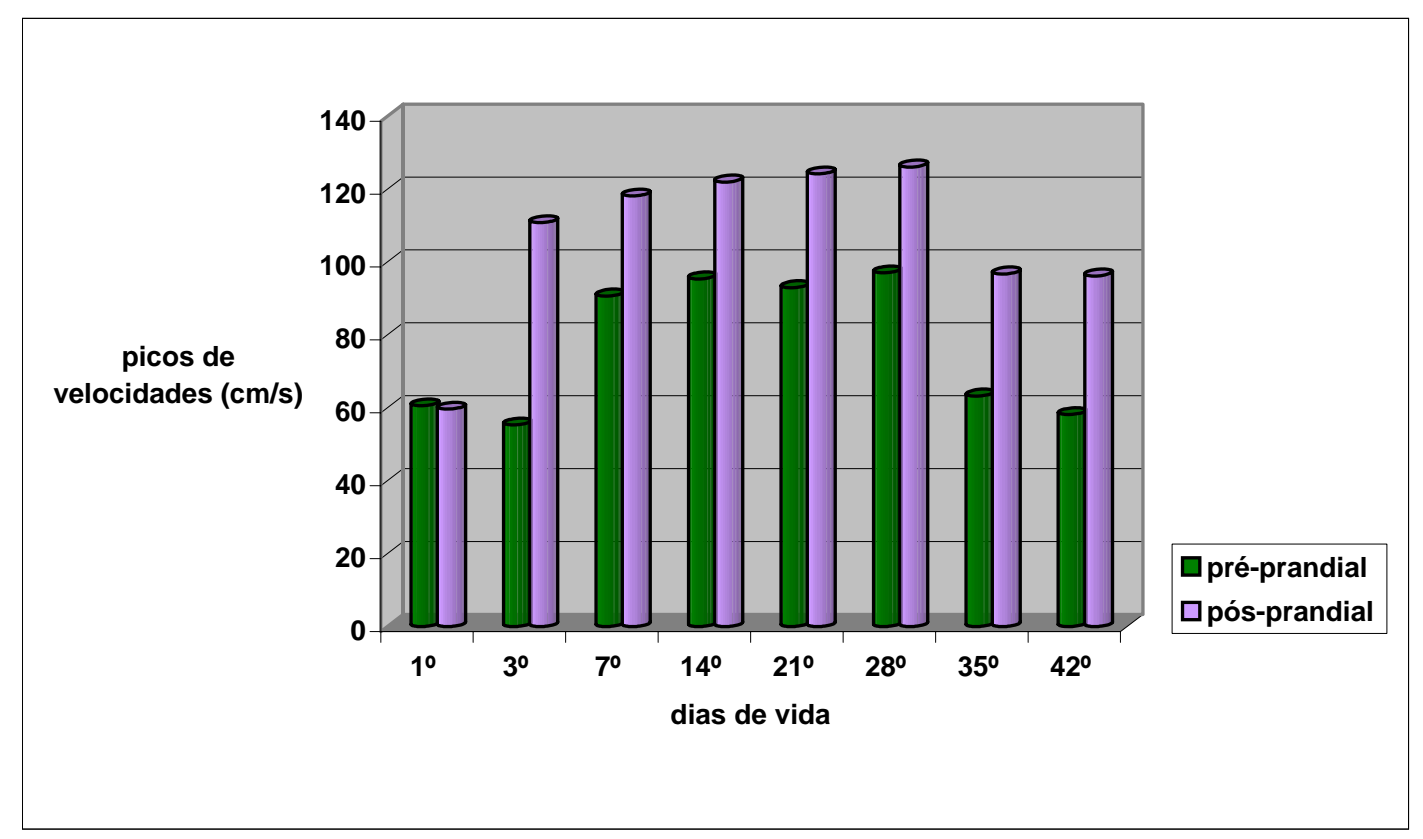

Gráfico 4- Médias de picos de velocidades diastólicas final (PVDF) pré e pós- prandiais, nas primeiras seis semanas de vida em $\mathrm{cm} / \mathrm{s}$

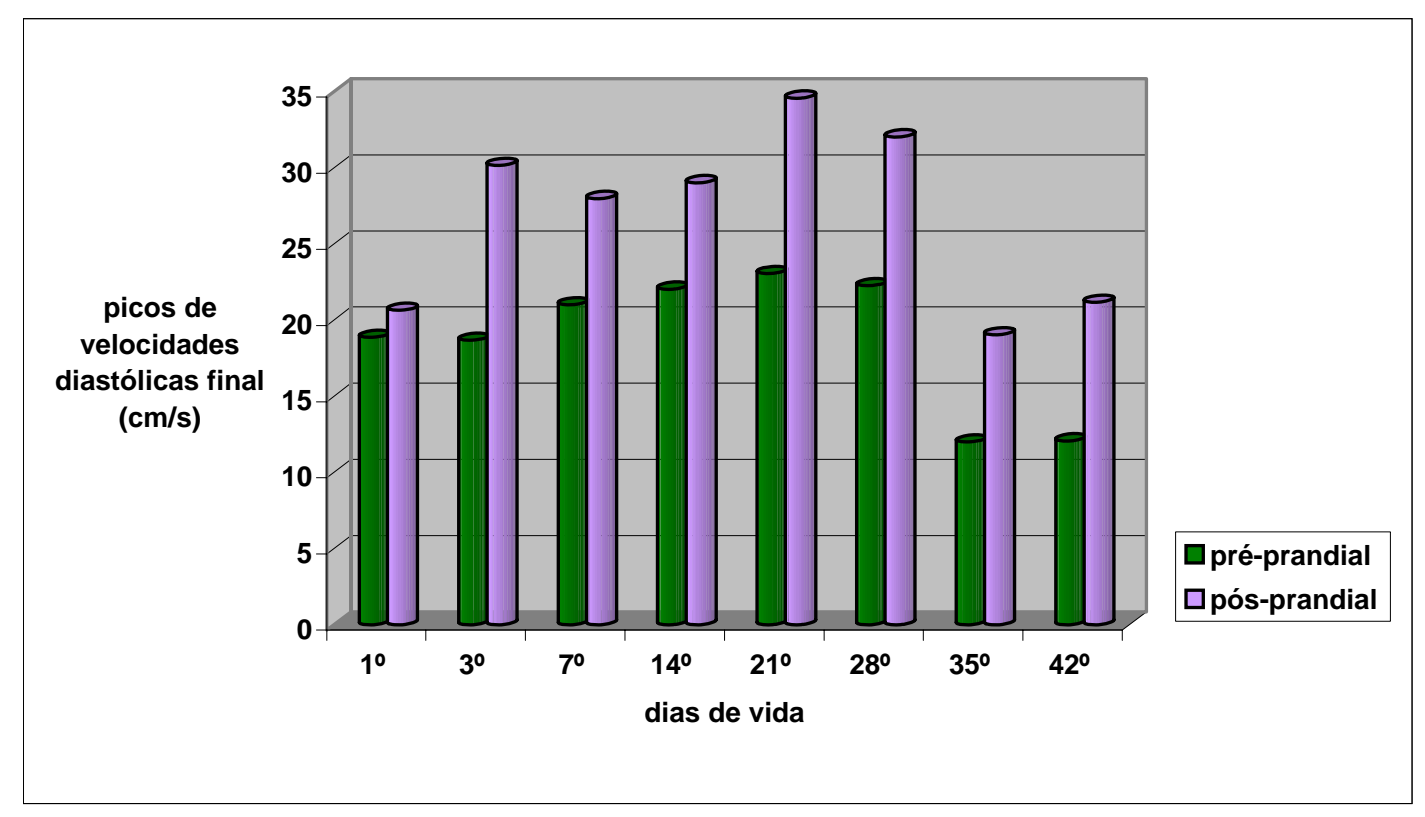


Por outro lado, quando se observa a variação $(\Delta)$ ou a intensidade da resposta de cada parâmetro frente à alimentação, pode-se notar que, as medidas de resistência vascular (IR e IP) mantêm-se invariáveis no decorrer da idade, com uma tendência à elevação no terceiro dia de vida. Enquanto que, as medidas de quantidade de fluxo sanguíneo, pico de velocidade sistólica e pico de velocidade diastólica final, mostram uma melhora desde os primeiros dias de vida e no decorrer das seis semanas de estudo.

Por fim, quando se observam os desvios padrão dos quatro parâmetros estudados, nota-se que apresentam valores mais elevados no primeiro, e particularmente no terceiro dias de vida, mostrando maior variação das medidas nestes dois períodos, estabilizando-se no final da primeira semana, até seis semanas de vida. 
5. Discussão 


\section{DISCUSSÃO}

Alterações do fluxo sanguíneo no território gastrintestinal têm sido descritas por muitos anos como sendo um dos principais fatores etiopatogênicos no desenvolvimento de doenças inflamatórias gastrintestinais tanto em crianças como em adultos (Nowick e Nankervis, 1994; Sato et al., 1987). Particularmente, na Medicina Neonatal, a enterocolite necrosante é uma entidade clínica bem caracterizada e cuja classificação baseia-se na apresentação clínica, gravidade e evolução. Ela é uma doença de etiologia multifatorial e de elevada morbimortalidade, sendo as alterações do fluxo sanguíneo local uma das causas implicadas na sua evolução (Hsueh et al., 2003), além da prematuridade.

Alguns estudos já descreveram a relação entre alterações do fluxo mesentérico e a ocorrência de intolerância alimentar ou de enterocolite necrosante no recém-nascido pré-termo (Bhatt et al., 2002), enquanto que outros demonstraram que características da resistência vascular mesentérica nos primeiros dias de vida poderiam ser um fator preditivo para o aparecimento de doenças gastrintestinais no período neonatal (Martinussen et al., 1996; Robel-Tilling et al., 2004; Murdoch et al., 2007). Estas pesquisas só puderam ser desenvolvidas a partir da evolução e do aperfeiçoamento da técnica de dopplerfluxometria em caracterizar o leito vascular mesentérico sendo, então, recentemente aplicada em recémnascidos (Coombs et al., 1992; Leidig, 1989). 
A dopplerfluxometria de onda pulsátil acoplada ao sistema de ultrasonografia convencional bidimensional, gerando o sistema duplex scan, permite identificar e selecionar o vaso específico a ser estudado, o que não seria possível se o exame fosse realizado por cada um dos sistemas descritos isoladamente (Weir et al., 1995).

A utilização de dopplerfluxometria da artéria mesentérica superior para medidas de velocidades e volumes de fluxo sanguíneo em adultos já está bem estabelecida (Leidig, 1989; Nakamura et al., 1989), no entanto, tecnicamente existem alguns fatores limitantes, pois devido à sua emergência da aorta ser próxima ao tronco celíaco, torna esta região sujeita a um fluxo turbulento, prejudicando, assim, o estabelecimento de medidas estáveis das velocidades de fluxo sanguíneo. Outro fator importante é o ângulo de insonação, que para esta técnica é aceitável em até vinte graus, pois acima desta angulação, o cosseno da equação do Doppler torna-se maior que um, sendo necessária aplicação de um fator de correção; aparelhos ultrassonográficos mais avançados como o que foi utilizado neste estudo tem um sistema intrínseco de autocorreção caso a angulação da medida do fluxo ultrapasse de vinte graus. Diferentemente do adulto, a estimativa dos volumes de fluxo sanguíneo da artéria mesentérica superior no recém-nascido pode não ser tão precisa, pois a rigor, esta medida necessita da determinação do diâmetro interno do vaso, e no período neonatal pode haver alguma porcentagem de erro devido ao pequeno calibre do vaso (Weir et al., 1995; Taylor et al., 1985). 
Apesar disto, já existe padrão estabelecido desta técnica para o período neonatal, pois algumas pesquisas já demonstraram a relação positiva entre o volume do fluxo estimado com o peso e a idade gestacional do recém-nascido (Van Bel et al., 1990). Em conseqüência às dificuldades técnicas de obtenção do volume de fluxo real do vaso estudado, a interpretação dos resultados é feita em conjunto com os índices de resistência, uma vez que a perfusão de um órgão depende das condições hemodinâmicas sistêmicas, em particular, do débito cardíaco (Agata et al., 1994).

Tendo em vista os aspectos de suma importância, baseados em observações clínicas, desde epidemiológicas, quadro clínico e complicações, até em relação a morbi-mortalidade, inclusive a evolução para seqüelas em doenças do trato gastrointestinal em $\mathrm{RN}$, em particular a enterocolite necrosante; vimos como essencial este trabalho, no sentido da possibilidade de se aplicar um método não invasivo, com resultado imediato e de valor preditivo para esta questão. E, para que se possa validar esta metodologia na prática clínica, buscou-se a identificação da normalidade dos índices da dopplerfluxometria da artéria mesentérica superior em RNPT em cada fase da sua evolução. Uma vez que o enfoque deste trabalho é essencialmente clínico, apesar do exame requerer recursos e treinamento técnico; no que diz respeito à efetivação deste trabalho, optou-se que os exames fossem realizados por três médicos com especialização em ultrassom e que receberam o mesmo treinamento para que os resultados possam ser confiáveis quanto à técnica. Estes três especialistas passaram por um 
refinamento técnico preliminar à coleta de dados deste trabalho, onde foram comparados os resultados obtidos por cada um deles em um mesmo recémnascido e no mesmo momento, diversas vezes, tendo sido notado que não houve diferença significativa entre os resultados obtidos por cada um, a validação dos resultados inter e intra-observador tem sido sugerido na literatura (Weir et al., 1995). A pesquisadora deste trabalho, por ser especialista clínica, não sendo habilitada tecnicamente quanto à realização de exames ultrassonográficos, realizou estudo teórico e treinamento técnico sobre dopplerfluxometria da artéria mesentérica superior em RN e acompanhou parte dos exames, os resultados por ela coletados somente foram validados após a conferência de um dos examinadores habilitados.

A dopplerfluxometria mesentérica superior é um método bem estabelecido em outras faixas etáreas, principalmente em adultos ou, então, como seguimento individual de alguma doença do trato gastrointestinal em particular. Em neonatologia, os trabalhos clínicos apresentavam grupos heterogêneos e, por vezes, com n reduzido.

A proposição do presente estudo baseia-se no fato de que o recémnascido pré-termo nasce em uma condição em que seus órgãos e sistemas ainda se encontram em amadurecimento; desta forma, o conhecimento das condições basais de irrigação sanguínea intestinal, em RN pré-termos saudáveis, torna-se um importante ponto de partida para a detecção precoce e prevenção da intolerância alimentar e até da enterocolite necrosante.

$\mathrm{Na}$ tentativa de reduzir ao máximo as situações que poderiam interferir no fluxo sanguíneo mesentérico, buscando a obtenção do padrão 
de normalidade destas medidas e o conhecimento de sua evolução em recém-nascidos prematuros, foi selecionada uma população de uma determinada faixa de idade gestacional e que apresentassem condições hemodinâmicas normais e estáveis e com adequação nutricional. Assim, fizeram parte do estudo apenas os recém-nascidos que apresentavam condições hemodinâmicas sistêmicas normais e estáveis (tabela 2), que não estivessem em uso fatores que já foram descritos como interferentes ao fluxo mesentérico, tais como: fototerapia, drogas vasoativas, xantinas ou indometacina e que não tivessem sido submetidos ao cateterismo umbilical.

Comprometimento do estado hemodinâmico do RN, como o choque ou a hipotensão gera a redistribuição do fluxo sistêmico (Agata et al., 1994), priorizando a irrigação de territórios cerebral, cardíaco e supra-renal, levando a vasoconstriç̧ão mesentérica; o uso de drogas vasoativas, por exemplo, a dopamina, nestas situações pode tanto melhorar como reduzir a perfusão mesentérica, seja por ação direta local da droga, seja por variar a condição hemodinâmica ( Hentschel et al., 1995; Zhang et al., 1999; Seri et al., 2002). Quadros infecciosos locais ou sistêmicos geram citoquinas inflamatórias que comprometem o fluxo sanguíneo mesentérico, sendo a mais conhecida a endotelina-1 (Weir et al., 1999; Hsueh et al., 2003), um potente vasoconstrictor; porém, em sepse neonatal precoce, pode ocorrer resposta inflamatória sistêmica semelhante ao do adulto, onde se nota uma hiperemia do leito esplâncnico e mesentérico. A irrigação mesentérica pode sofrer também alterações diante de situações necessárias na terapêutica do recém-nascido prematuro, tais como o tipo de fototerapia que é utilizada 
para tratamento de icterícia do recém-nascido; a fototerapia convencional bloqueia a hiperemia funcional em resposta à dieta (Pezzati et al., 2000); a administração da indometacina para tratamento da persistência do ducto arterial em recém-nascidos prematuros leva à vasoconstricção mesentérica, comprometendo a perfusão intestinal (Yanowitz et al., 1998); a cafeína é utilizada para tratamento da apnéia da prematuridade e leva a redução do fluxo sanguíneo cerebral e intestinal, sem alterar as condições hemodinâmicas (Hoecker et al., 2002). O cateterismo de vasos umbilicais, muitas vezes necessária como um procedimento para manutenção de acesso vascular e meio para monitorização hemodinâmica do recém-nascido gravemente enfermo, tem sido relacionado ao aumento de risco para condições de morbidade do sistema intestinal, pela redução do calibre para o fluxo sanguíneo efetivo e lesão endotelial com liberação de fatores inflamatórios ( Rand et al., 1996; Roll e Hanssler, 1998; Shah et al., 1998).

Foram excluídos também, recém-nascidos de mães que apresentaram condição de morbidade que pudesse interferir com o fluxo mesentérico. Alteração do fluxo sanguíneo mesentérico na vida intra-uterina pode ocorrer em situações de doenças maternas tais como hipertensão arterial, trombofilias, infecções e a ocorrência de restrição do crescimento intra-uterino (Edelstone e Holzman, 1982), levando a uma redistribuição do fluxo sanguíneo com direcionamento preferencial aos órgãos como o cérebro e o coração principalmente, reduzindo a irrigação do território mesentérico. Esta condição pode persistir por algum período após o nascimento e está relacionado à dificuldade de alimentação e maior risco de 
evolução para quadros de intolerância alimentar, desde um simples íleo adinâmico até a apresentação de enterocolite necrosante (Fang et al., 2001).

De acordo com o padrão que foi proposto como critério de inclusão deste estudo, houve, com muita freqüência, a impossibilidade de realização do exame no mesmo recém-nascido que inicialmente foi incluído no estudo, num determinado momento da sua vida; seja por instabilidade hemodinâmica, muito freqüente no terceiro dia de vida pela condição do canal arterial patente ou por necessidade de suporte ventilatório agressivo, podendo comprometer o débito cardíaco; seja por uma intercorrência na sua evolução, tais como, sepse ou intolerância alimentar. Da mesma forma, quanto mais prematuro ao nascimento, mais este recém-nascido foi susceptível às condições de morbidade materna que levaram ao nascimento prematuro, assim como, maior foi o risco de ocorrência de asfixia perinatal, podendo não somente comprometer o fluxo mesentérico, como fazer com que se prolongue a situação de instabilidade hemodinâmica, limitando o número de casos incluídos no extremo inferior da prematuridade e nos primeiros dias de vida. Além disso, como muitas vezes o nascimento prematuro configura-se num caso de urgência, dependendo do momento do horário de nascimento, torna-se impossível a realização do exame do primeiro dia por motivos de disponibilidade da equipe, limitando também o número de casos estudados do primeiro dia. Outras questões que limitaram a quantidade de casos estudados no período proposto referem-se a fatores necessárias a terapêutica a que freqüentemente o recém-nascido prematuro é submetido na sua evolução neonatal precoce, tais como , a necessidade 
de fototerapia, cateterismo umbilical para monitorização hemodinâmica e administração de infusões endovenosas, uso de xantinas em caso de evolução para quadros de apnéia ou de indometacina para fechamento de canal arterial patente, que sabidamente interferem com o fluxo mesentérico. Os fatores acima descritos justificam o número reduzido, porém homogêneo, de casos estudados.

Em relação à alimentação, o tempo aceitável para as medidas pósprandiais são descritos a partir de 30 minutos, sendo o pico das velocidades de fluxo em 50 minutos, até o máximo de 90 minutos; não há consenso se existem diferenças quanto à alimentação por sucção própria ou por gavagem, assim como, quanto ao tipo dieta, leite humano ou fórmula; na maioria dos estudos, em RN saudáveis, é esperada uma resposta vasodilatadora mesentérica pós-prandial (Leidig, 1989; Van Bel et al., 1990; Coombs et al., 1992); mais recentemente estudos têm enfatizado ainda mais benefícios do leite materno (Bellander et al.,2003; Snirivasan et al., 2008), além de retomar à discussão os benefícios da sucção não nutritiva antes da alimentação enteral propriamente dita em RNPT (Huang et al., 2003). Por outro lado, no recém-nascido, o intestino tem uma capacidade limitada de gerar radicais livres, pela menor atividade da xantina oxidase e menor quantidade de neutrófilos aderidos ao endotélio. Porém, este mecanismo de lesão pode estar exacerbado em recém-nascidos expostos à dieta enteral formulada, sendo relacionado ao conteúdo dietético de lipídios (Crissinger et al., 1992; Snirivasan et al., 2008), levando à resposta vasoconstrictora, podendo ser preditivo de morbidade gastro-intestinal. 
A análise descritiva dos resultados deste estudo mostra uma melhora significativa do fluxo sanguíneo mesentérico superior relacionado à idade pós-natal, representado pelos picos de velocidade sistólica e diastólica final (tabela 4, gráfico 3 e 4), além da melhora da resposta vasodilatadora após a alimentação, mostrando que houve não somente um amadurecimento na quantidade de fluxo sanguíneo basal, como também da resposta à alimentação, demonstrando tolerância à dieta administrada. A elevação transitória dos índices de resistência vascular (IR e IP) no terceiro dia em relação ao primeiro dia pode ser ainda uma condição fisiológica do final do período de transição da circulação fetal para a pós-natal no período neonatal precoce, onde a resistência vascular mesentérica ainda pode estar um pouco elevada (tabela 3, gráfico 1 e 2), dados estes concordantes com as pesquisas de Maruyama e colaboradores (1999), sendo que, a maioria dos autores (Van Bel et al., 1990; Agata et al., 1994; Nowicki e Nankervis, 1994; Pezzati et al., 2004) admite estabilização dos fluxos em órgãos periféricos a partir do quinto dia de vida; sendo assim, os resultados das medidas do índice de resistência, do pico de velocidade sistólica e do pico de velocidade diastólica final são bastante significativos. A maioria dos estudos clínicos correlaciona a evolução do fluxo mesentérico com a idade pós-natal precoce, particularmente na primeira semana de vida, enquanto que outros descrevem a associação de alteração deste fluxo com a intolerância alimentar ou, ainda, em estudos com recém-nascidos de termo, quando o exame é realizado em um único momento, sem o detalhamento do dia de vida (Leidig, 1989; Van Bel et al., 1990; Coombs et al., 1992). 
Desta forma, em comparação com os resultados pontuais obtidos com neonatos de termo, os índices de resistência pré-prandias são mais baixos nos prematuros e apresentam uma vasodilatação pós-prandial mais exacerbada, particularmente no terceiro dia de vida, porém mais variável (maior desvio padrão), atingindo valores próximos ao do recém-nascido de termo por volta da quarta para quinta semana de vida. Recém-nascidos prematuros apresentam menor resistência vascular e maior fluxo diastólico no território mesentérico que recém-nascidos de termo (Martinussen et al., 1996). Esta diferença pode ser explicada pela baixa resistência vascular geral do prematuro ou pela baixa resistência vascular seletiva devido ao crescimento rápido intestinal do recém-nascido (Nowicki e Edwards, 1992), sendo que a maior quantidade local de óxido nítrico (um potente vasodilatador) encontrado no prematuro, em relação ao recém-nascido de termo, é um dos fatores implicados. A vasodilatação funcional após a alimentação enteral em recém-nascidos de termo já é bem conhecida (Van Bel et al., 1990; Coombs et al., 1992). Por outro lado, o prematuro apresenta esta resposta, às vezes variável, e requer compensações hemodinâmicas sistêmicas, como o aumento do débito cardíaco, muitas vezes com redução da pressão arterial (Robel-Tilling et al., 2004), levando à uma alteração momentânea de hipotensão, quedas de saturação, podendo gerar repercussões como cianose, hipoatividade e incoordenação na deglutição.

Quanto às velocidades de fluxo, os valores pré-prandias são mais baixos, atingindo os níveis dos primeiros dias do termo até o sétimo dia de vida quanto ao fluxo sistólico, porém a resposta do aumento do fluxo pós- 
prandial já mostra a mesma eficiência no terceiro dia de vida, em recémnascidos alimentados. O fluxo diastólico basal apresenta valores mais elevados que os do termo, podendo ser um sinal de imaturidade. Os valores de fluxo atingem os níveis do recém-nascido de termo a partir do final do primeiro mês de vida, momento em que se nota também aumento dos índices de resistência vascular.

Por tratar-se de uma análise descritiva, uma vez que este estudo partiu-se do princípio de incluir uma população homogênea quanto às condições clínicas e hemodinâmicas saudáveis e com boa tolerância à alimentação e tendo sido adotado como metodologia o estudo de coorte, não apresentamos nenhum resultado baseado em análise comparativa, já que o $\mathrm{n}$ entre as faixas de idade gestacional pós-natal são muito diferentes entre eles, não se permitindo à comparação. Ademais, os resultados obtidos representam a normalidade do recém-nascido no seu momento de vida, sendo que, independente da relevância estatística que porventura possa existir caso seja aplicado algum método de análise comparativa entre as faixas de idade pós-natal, estes resultados demonstram a evolução normal esperada do RN nos seus dias de vida, quanto ao fluxo mesentérico.

Vale comentar que no princípio deste estudo, houve a intenção de se identificar se o fluxo sanguíneo mesentérico apresentaria uma evolução, caracterizando uma maturação, acompanhando a evolução da idade pósconceptual ou a evolução da idade pós-natal. Quando os resultados foram distribuídos de acordo com a idade pós-conceptual, os dados se mostraram dispersos, não permitindo a nenhuma descrição que caracterizasse o grupo. 
Além disso, como objetivo secundário deste estudo, foi realizada a análise das medidas do Doppler mesentérico em relação à sua evolução diante do estímulo da alimentação enteral; assim, foi possível identificar que a partir do estímulo alimentar, cada grupo de estudo apresentou uma evolução peculiar que poderia não ser possível na ausência da alimentação.

À luz do conhecimento da fisiologia e da fisiopatologia da circulação intestinal do recém-nascido baseado em estudos experimentais, os resultados obtidos podem ser justificados pelos seguintes dados. $O$ prematuro nasce em condição de imaturidade intestinal, tanto histológica como funcional, onde os vasos encontram-se num tônus basal mais relaxados e pouco ramificados (Reber et al., 2002), o que justifica os índices de resistência basais mais baixos; além disso, a imaturidade de estímulo nervoso e da resposta a este estímulo gera respostas adversas e mais latentes, o que pode justificar a variabilidade da resposta pós-prandial no terceiro dia de vida. Por outro lado, em recém-nascidos estáveis e precocemente alimentados, existe um estímulo precoce por elementos da alimentação (p.ex, a glutamina) (Carver et al., 2002; Mercier et al., 2003), gerando respostas neuro-endócrinas, levando à regulação do balanço entre a vasoconstricção e a vasodilatação oferecido por, principalmente, endotelina e óxido nítrico intestinal respectivamente (Aynsley-Green et al., 1977; Reber et al., 2002) e a liberação de fatores tróficos intestinais que promovem a proliferação e a diferenciação do tecido intestinal, justificando a resposta pós-prandial eficiente a partir do sétimo dia de vida. Da mesma maneira, o estímulo da alimentação promove diferenciação vascular com 
aumento das ramificações e a capilarização dos ramos com diminuição dos diâmetros vasculares, levando ao fluxo turbulento, o que pode justificar a elevação dos índices de resistência e a diminuição dos valores de fluxo sanguíneo ao final do primeiro mês de vida o que, contraditoriamente, são sinais de maturidade intestinal (Reber et al., 2002), pois atingem valores próximos aos do recém-nascido de termo. Além disso, a maturação do estímulo e da resposta a este estímulo da inervação adrenérgica extrínseca é também responsável pelo aumento do tônus vascular (Nankervis et al., 2001b). Experimentalmente, estas respostas não são encontradas em casos de restrição alimentar e nutrição parenteral exclusiva (Lucas et al., 1980).

Da mesma forma que alguns trabalhos utilizaram o termo maturidade intestinal, referindo-se a diversos sistemas fisiológicos que compõem o trato gastrointestinal (Reber et al., 2002; Nankervis et al., 2001b), outros mais recentes reforçam esta mesma idéia principalmente quando se estuda a evolução clínica do recém-nascido prematuro frente a diversas condições ( Bellander et al., 2003; Huang et al., 2003; Srinivasan et al., 2008). Estas razões nos levaram a manter o título original desta tese com o termo maturação, apesar desta palavra ser pouco específica, uma vez que a intenção foi de mostrar que existe uma mudança evolutiva do fluxo sanguíneo da artéria mesentérica superior, detectável por um método não invasivo que é a dopplerfluxometria. 
6. Conclusões 


\section{CONCLUSÕES}

- Recém-nascidos prematuros saudáveis de idade gestacional menor ou igual a 34 semanas completas e maiores de 27 semanas de idade gestacional ao nascimento, apresentam, por meio da dopplerfluxometria, características peculiares do fluxo sanguíneo da artéria mesentérica superior e mudanças destes parâmetros de acordo com a evolução da idade gestacional pós-natal;

- Recém-nascidos prematuros saudáveis de idade gestacional menor ou igual a 34 semanas completas e maiores de 27 semanas de idade gestacional ao nascimento, apresentam mudanças dos parâmetros da dopplerfluxometria características, frente à condição fisiológica da alimentação enteral e de acordo com a evolução da idade gestacional pós-natal. 
7. Considerações finais 


\section{CONSIDERAÇÕES FINAIS}

Recém-nascidos pré-termo saudáveis e com boa tolerância alimentar, apresentam uma evolução do fluxo sanguíneo mesentérico peculiar e resposta vasodilatadora frente à alimentação significativa logo nos primeiros dias de vida, atingindo a semelhança com recém-nascidos de termo ao final do primeiro mês de vida.

O conhecimento da normalidade dos índices de fluxo sanguíneo da artéria mesentérica superior poderão indicar a dopplerfluxometria como um método de avaliação de rotina mais específico para cada recém-nascido prétermo, como um indicador para a introdução da dieta e também para uma progressão mais segura da alimentação enteral, reduzindo a ocorrência de quadros gastrintestinais; objetivando a melhoria da assistência perinatal, com a redução da morbimortalidade, dos custos do tratamento e do tempo de internação, evitando complicações e minimizando a ocorrência de seqüelas em cada recém-nascido.

Assim, a dopplerfluxometria da artéria mesentérica superior poderá ser um importante instrumento preventivo na avaliação das condições alimentares individuais de recém-nascidos pré-termo, podendo também auxiliar na determinação do tipo e volume da dieta que cada neonato melhor toleraria (Fang et al, 2001; Havranek et al, 2006).

Porém, este estudo necessita de outros por vir, principalmente de cunho multicêntrico, a fim de se obter curvas de padrão de normalidade, tanto dos índices de resistência, quanto de velocidades de fluxo sanguíneo, 
como referência na literatura. Enquanto isso, os resultados deste estudo sugerem valores de normalidade para cada parâmetro da dopplerfluxometria mesentérica superior, sendo que os resultados obtidos para cada recémnascido que for aplicado esta metodologia, serve de referência individual na evolução clínica específica da perfusão sanguínea do território da artéria mesentérica superior, o que pode predizer as condições de tolerância alimentar deste recém-nascido.

Em crianças maiores, a dopplerfluxometria mesentérica pode auxiliar no acompanhamento de quadros de doenças inflamatórias intestinais e de intolerância alimentar, como por exemplo, nas alergias alimentares, onde um dos mecanismos implicados é o desbalanço imunológico entre citoquinas de tolerância oral e as responsáveis por alergias ou quadros inflamatórios intestinais (Kaliomäki et al, 2001 ; Hooper et al, 2003).

Outros estudos prospectivos bem delineados deverão ainda ser realizados para se obter o conhecimento dos valores normais dos índices de resistências e de velocidades de fluxo, assim como a quantificação da resposta à alimentação em toda a faixa pediátrica e em doenças gastrointestinais específicas. 
8. Anexos 


\section{TERMO DE CONSENTIMENTO}

\section{HOSPITAL E MATERNIDADE SÃO LUIZ}

SERVIÇO DE NEONATOLOGIA

E

HOSPITAL DAS CLÍNICAS

DA

FACULDADE DE MEDICINA DA UNIVERSIDADE DE SÃO PAULO

\section{TERMO DE CONSENTIMENTO LIVRE E ESCLARECIDO}

(Instruções para preenchimento no verso)

I - DADOS DE IDENTIFICAÇÃO DO SUJEITO DA PESQUISA OU RESPONSÁVEL LEGAL

1. NOME DO PACIENTE

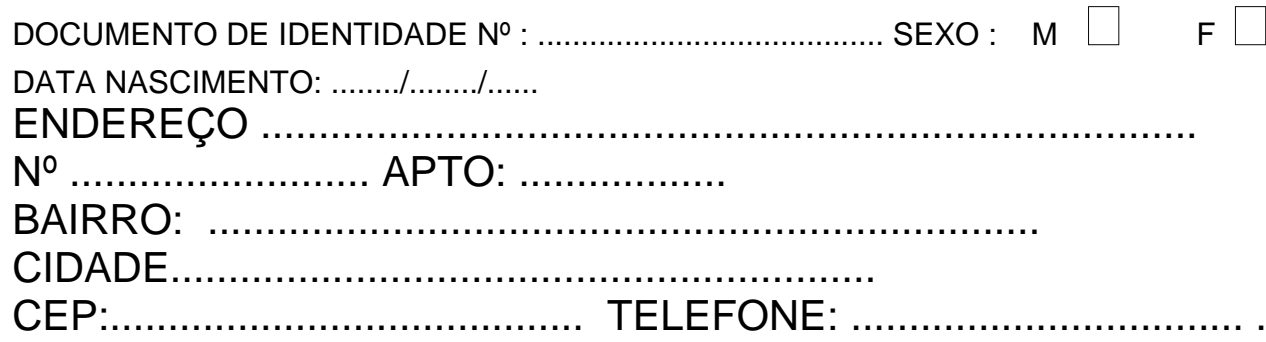

BAIRRO:

CIDADE.

CEP:

TELEFONE:

2.RESPONSÁVEL LEGAL

NATUREZA (grau de parentesco, tutor, curador etc.)

DOCUMENTO DE IDENTIDADE SEXO: $M$ $\mathrm{F}$ DATA NASCIMENTO.: ..................... ENDEREÇO: $\mathrm{N}^{\circ}$ APTO BAIRRO: CIDADE: CEP:. TELEFONE: ...). 
1. TÍtULO dO PROTOCOLO DE PESQUISA: ESTUdO DA MATURAÇÃO DA RESPOSTA VASCULAR DA ARTÉRIA MESENTÉRICA SUPERIOR EM RECÉM-NASCIDOS PREMATUROS ATRAVÉS DO DOPPLERFLUXOMETRIA.

2. PESQUISADOR RESPONSÁVEL: CHANG YIN CHIA

CARGO/FUNÇÃO: MÉDICA

INSCRIÇÃO CONSELHO REGIONAL No 72.499

UNIDADE DO HCFMUSP: DEPARTAMENTO DE PEDIATRIA

3. AVALIAÇÃO DO RISCO DA PESQUISA:

$\begin{array}{llll}\text { SEM RISCO } & X & \text { RISCO MÍNIMO } \\ \text { RISCO BAIXO } & \square & \text { RISCO MAIOR }\end{array}$

(probabilidade de que o indivíduo sofra algum dano como consequência imediata ou tardia do estudo)

4. DURAÇÃO DA PESQUISA : DOIS ANOS 


\section{III - REGISTRO DAS EXPLICAÇÕES DO PESQUISADOR AO PACIENTE OU SEU REPRESENTANTE LEGAL SOBRE A PESQUISA, CONSIGNANDO:}

1. ¿ustificativa e os objetivos da pesquisa - Prezados pais, o seu filho(a) nasceu antes da data prevista, por isso, ele(a) é prematuro(a), ou seja, os seus órgãos são imaturos e corre o risco de apresentar algumas dificuldades na sua evolução clínica. Um destes problemas pode ser a dificuldade de aceitar a alimentação, o leite, quando ele for iniciado ou de permitir que a quantidade deste leite seja aumentada diariamente para permitir um ganho de peso esperado para a sua evolução. Este problema pode estar relacionado às dificuldades clínicas que o seu bebê está passando neste momento ou pode ser um problema da imaturidade do seu trato digestivo. Um exame que existe que possa indicar as condições do seu trato digestivo é estudando a artéria que leva o sangue para os intestinos. Se a quantidade de sangue que está chegando aos intestinos está adequada e esta quantidade aumenta de maneira esperada após a alimentação, leva a supor que o intestino está em condições de tolerar o leite de maneira esperada. Na verdade, a quantidade de sangue (o fluxo) e o quanto varia esta quantidade são bem conhecidas em adultos e em crianças não prematuras. Em crianças prematuras esperamos a mesma resposta, mas pode ser que exista uma diferença de acordo com a idade gestacional que ele (a) nasceu. Assim, gostaríamos que o seu filho(a) seja submetido(a) a este exame e o resultado do mesmo seja incluído numa pesquisa para que se possa estabelecer quais são os valores do fluxo de sangue que passa aos intestinos de acordo com a idade gestacional e se existe alteração deste fluxo diante de algumas condições de tratamento que o seu filho(a) venha a ser submetido, caso precise, como por exemplo, o banho de luz artificial. O bebê deve realizar os exames no primeiro, no terceiro e no sétimo dias de vida, e depois uma vez por semana até a alta hospitalar. Os exames serão realizados durante a internação do bebê, dentro do Berçário da Maternidade São Luiz. Os resultados dos exames serão analisados em conjunto com o Departamento de Pediatria do Hospital das Clínicas da Faculdade de Medicina da Universidade de São Paulo.

2. procedimentos que serão utilizados e propósitos, incluindo a identificação dos procedimentos que são experimentais - O exame chama-se dopplerfluxometria da artéria mesentérica superior e é realizado através do ultrassom na região superior do abdômen.

3. desconfortos e riscos esperados - nenhum

4. benefícios que poderão ser obtidos - conforme os resultados, podemos ter maior segurança em dar o leite ao seu recém-nascido e saber se pode ou não aumentar este leite . Caso ele não tenha condições de receber o leite, podemos estar evitando complicações que possa atrapalhar a sua evolução clínica.

5. procedimentos alternativos que possam ser vantajosos para o indivíduo.- nenhum

6. despesas financeiras acarretadas ao paciente ou ao seu responsável legal - nenhuma 


\section{IV - ESCLARECIMENTOS DADOS PELO PESQUISADOR SOBRE GARANTIAS DO SUJEITO DA PESQUISA:}

1. acesso, a qualquer tempo, às informações sobre procedimentos, riscos e benefícios relacionados à pesquisa, inclusive para dirimir eventuais dúvidas. SIM

2. liberdade de retirar seu consentimento a qualquer momento e de deixar de participar do estudo, sem que isto traga prejuízo à continuidade da assistência. -SIM

3. salvaguarda da confidencialidade, sigilo e privacidade. - SIM

4. viabilidade de indenização por eventuais danos à saúde decorrentes da pesquisa - não existem danos esperados até o momento, pois o exame é inócuo, indolor e não invasivo.

\section{INFORMAÇÕES DE NOMES, ENDEREÇOS E TELEFONES DOS RESPONSÁVEIS PELO ACOMPANHAMENTO DA PESQUISA, PARA CONTATO EM CASO DE INTERCORRÊNCIAS CLÍNICAS E REAÇÕES ADVERSAS.}

\section{OBSERVAÇÕES COMPLEMENTARES:}

\section{VII - CONSENTIMENTO PÓS-ESCLARECIDO}

Declaro que, após convenientemente esclarecido pelo pesquisador e ter entendido o que me foi explicado, consinto em participar do presente Protocolo de Pesquisa. São Paulo, de de 2 .......... 
2. FICHA DE COLETA DE DADOS 


\section{Referências}

De acordo com:

Adaptado de International Committee of Medical Journals Editors (Vancouver).

Universidade de São Paulo, Faculdade de Medicina.

Serviço de Biblioteca e Documentação.

Guia de apresentação de dissertações, teses e monografias da FMUSP.

Elaborado por Anneliese Carneiro da Cunha, Maria Julia A. L. Freddi, Maria F. Crestana, Marinalva de , S. Aragão, Suely C. Cardoso, Valéria Vilhena.

São Paulo: Serviço de Biblioteca e Documentação; 2004.

Abreviatura dos títulos dos periódicos de acordo com List of Journals Indexed in Index Medicus. 


\section{REFERÊNCIAS}

Agata Y, Hiraishi S, Misawa H, Hirota H, Nowatari M, Hiura K, Fujino N, Oguchi K, Horiguchi Y. Regional blood flow distribution and left ventricular output during early neonatal life: a quantitative ultrasonographic assessment. Pediatr Res. 1994;36:805-10.

Amer MD, Hedlund E, Rochester J, Caplan MS. Platelet-activating factor concentration in the stool of human newborn effects of enteral feeding and neonatal necrotizing enterocolitis. Biol Neonate. 2004;85:159-66.

Aynsley-Green A, Bloom SR, Williamson DH, Turner RC. Endocrine and metabolic response in the human newborn to first feed of breast milk. Arch Dis Child. 1977;52:291-5.

Bellander M, Ley D, Polberger S, et al. Tolerance to early human milk feedings is not compromised by indomethacin in preterm infants with persistent ductus arteriosus. Acta Paediatr. 2003; 92(9):1074-1078.

Berseth CL. Gastrointestinal and nutricional condicions (part XI) Developmental anatomy and physiology of the gastrointestinal tract. In: Taeusch HW, Ballard RA (ed). Avery's diseases of the newborn. 7th ed. Philadelphia: Saunders Company; 1998. p.893-904.

Bhatt AB, Tank PD, Barmade KB, Damania KR. Abnormal doppler flow velocimetry in the growth restricted fetus as a predictor for necrotizing enterocolitis. J Postgrad Med. 2002;48:182-5.

Bocuvalas JC, Balistreri WF. The neonatal gastrointestinal tract (part 1) Development. In: Fanaroff AA, Martin RJ (ed). Neonatal perinatal medicine: 
diseases of the fetus and infant. 5a ed. St Louis: Mosby year book; 1992. p.1019-23.

Bude RO, Larson RG, Nichols WW, Rubin JM. Stenosis of the main artery supplying an organ: effect of end-organ vascular resistance on the poststenotic peak systolic velocity in an in vitro hydraulic model at Doppler US. Radiology 1999;212:79-87.

Carver JD, Saste M, Sosa R, Zaritt J, Kuchan M, Barness LA. The effects of dietary nucleotides on intestinal blood flow in preterm infants. Pediatr Res. 2002;52:425-9.

Coombs RC, Morgan MEI, Durbin GM, Booth IW, McNeish AS. Doppler assessment of human neonatal gut blood flow velocities: postnatal adaptation and response to feeds. J Pediatr Gastroenterol Nutr. 1992;15:612.

Crissinger K, Grisham J, Granger D. Developmental biology of oxidantproducing enzymes and antioxidants in the piglet intestine. Pediatr Res. 1989;25:612-6.

Crissinger K, Kvietys P, Granger D. Developmental intestinal vascular responses to venous pressure elevation. Am J Physiol. 1988;254:G658-63.

Crissinger K, Tso P, Burney D. The role of lipids in ischemia/reperfusioninduced changes in mucosal permeability in developing piglets.

Gastroenterology. 1992;102:1693-9.

Davis AJ, Jobe AH, Häfner D, Ikegami M. Lung function in premature lambs and rabbits with a recombinant SP-C surfactant. Am J Respir Crit Care Med. 1998;157:553-9.

DeCobelli F, Cappio S, Del Maschio A. Noninvasive imaging of the abdominal vessels. Rays. 2001;26:269-76. 
Edelstone D, Holzman I. Fetal intestinal oxygen consumption at various levels oxygenation. Am J Physiol. 1982;242:H50-4.

Edelstone D, Holzman I. Gastrointestinal tract $\mathrm{O}_{2}$ uptake and regional blood flows during digestion in conscious newborn lambs. Am J Physiol. 1981;241:G289-93.

Evans N, Kluckow M, Simmons M, Osborn D. Which to measure, systemic or organ blood flow? Middle cerebral artery and superior vena cava flow in very preterm infants. Arch Dis Child Fetal Neonatal Ed. 2002;87:F181-F184.

Ewer AK. Role of Platelet-activating factor in the pathophysiology of necrotizing enterocolitis. Acta Paediatr Suppl. 2002;91(437):2-5.

Fang S, Kempley ST, Gamsu HR. Prediction of early tolerance to enteral feeding in preterm infants by measurement of superior mesenteric artery blood flow velocity. Arch Dis Child Fetal Neonatal Ed. 2001;85:F42-F5.

Gosling RG, King DH. Ultrasound angiology. In: Marcus AW, Adamson L. Arteries and veins. Edinburgh: Churchill Livingstone; 1975. p.61-98.

Granger D, Benoit J, Suzuki M, Grisham MB. Leucocyte adherence to venular endothelium during ischemia-reperfusion. Am J Physiol. 1989;257:G683-8.

Granger D, Kvietys P, Perry M. Role of exchange vessels in the regulation of intestinal oxygenation. Am J Physiol. 1982;242:G570-4.

Granger D, Rutili G, Mc Cord J. Superoxide radicals in feline intestinal ischemoia. Gastrenterology. 1981;81:22-9.

Granger $\mathrm{H}$, Shepherd A. Dynamics and control of the microcirculation. Adv Biomed Engr Med Phys. 1979;7:1. 
Grassi M, Costa MT, Vaz FAC. Fatores imunológicos do leite humano. Pediatria (São Paulo). 2001;23:258-63.

Grisham M, Hernandez L, Granger D. Xanthine oxidase and neutrophil infiltration in intestinal ischemia. Am J Physiol. 1986;251:G567-74.

Hackett GA, Campbell S, Gamsu H, Cohen-Overbeek T, Pearce JM. Doppler studies in the growth retarded fetus and prediction of necrotizing enterocolitis, haemorrhage and neonatal morbidity. Br Med J (Clin Res Ed). 1987;294(6563):13-6

Havranek T, Johanboeke P, Mandramootoo C, Carver JD. Umbilical artery catheters do not affect intestinal blood flow responses to minimal enteral feedings. J Perinatol. 2007;27:375-9.

Havranek T, Thompson Z, Carver JD. Factors that influence mesenteric artery blood flow velocity in newborn preterm infants. J Perinatol. 2006;26:493-7.

Hentschel R, Hensel D, Brune T, Rabe H, Jorch G. Impact on blood pressure and intestinal perfusion of dobutamine or dopamine in hypotensive preterm infants. Biol Neonate. 1995;68:318-24.

Hoecker C, Nelle M, Poeschl J, Beedgen B, Linderkamp O. Caffeine impairs cerebral and intestinal blood flow velocity in preterm infants. Pediatrics. 2002;109:784-7.

Hooper LV, Stappenbeck TS, Hong CV, Gordon JI. Angiogenins: a new class of microbicidal proteins involved in innate immunity. Nat Immunol. 2003;4:269-73.

Hsueh W, Caplan MS, Qu XW, Tan XD, De Plaen IG, Gonzalez-Crussi F. Neonatal necrotizing enterocolitis: clinical considerations and pathogenetic concepts. Pediatr Dev Pathol. 2003;6:6-26. 
Hsueh W, Gonzales-Crussi F, Arroyave J. Platelet-activating factor-induced ischemic bowel necrosis. Am J Pathol. 1986;122:231-9.

Hsueh W, Gonzales-Crussi F, Arroyave J. Release of leucotriene C4 by isolated, perfused rat small intestine in response to platelet-activing factor. $J$ Clin Invest. 1986;78:108.

Huang CF, Tsai MC, Chu $\mathrm{CH}$, et al. The influence of pacifier sucking on mesenteric blood flow in infants. Clin Pediatr (Phila). 2003;42(6):543-6.

Ikegami M. Surfactant inactivation. In: Boyton BR, Carlo WA, Jobe AH, editors. New therapies for neonatal respiratory failure. 1st ed. Cambridge: University Press; 1994. p.36-48.

Kaliomäki M, Kirjavainen P, Eerola E, Kero P, Salminen S, Isolauri E. Distinct patterns of neonatal gut microflora in infants in whom atopy was and was not developing. J Allergy Clin Immunol. 2001;107:129-34.

Kempley ST, Murdoch E. Splanchnic haemodynamic disturbances in perinatal sepsis. Arch Dis Child Fetal Neonatal Ed. 2000;83:F139-F142.

Kenneth JW, Taylor MD. Blood flow in deep abdominal and pelvic vessels: ultrasonic pulsed-doppler analysis. Radiology. 1985;154:487-93.

Kenneth JW, Taylor MD. Doppler US - Part I. Basic Principles, Instrumentation, and Pitfalls. Radiology. 1990;174:297-307.

Kluckow M, Evans N. Superior vena cava flow in newborn infants: a novel marker of systemic blood flow. Arch Dis Child Fetal Neonatal Ed. 2002;82:F182-F187. 
Korszun P, Dubiel M, Breborowicz G, Danska A, Gudmun S. Fetal superior mesenteric artery blood flow velocimetry in normal and high-risk pregnancy. $J$ Perinatol Med. 2002;30:235-41.

Kvietys P, Granger D. Relation between intestinal blood flow and oxygen uptake. Am J Physiol. 1982;242:G202-8.

Lane AJP, Coombs RC, Evans DH, Levin RJ. Effect of feed interval and feed type on splanchnic haemodynamics. Arch Dis Child Fetal Neonatal Ed. 1998;79:F49-F53.

Langman J. Embriologia médica-desenvolvimento humano normal e anormal. 3a ed. São Paulo: Atheneu; 1977. p.201-10.

Langman J. Embriologia médica-desenvolvimento humano normal e anormal. 3a ed. São Paulo: Atheneu; 1977. p.244-59.

Le Blanc M, D'Cruz C, Pate K. Necrotizing enterocolitis can be caused by polycythemic hyperviscosity in the newborn dog. J Pediatr. 1984;105:804.

Leidig E. Pulsed Doppler ultrasound blood flow measurements in the superior mesenteric artery of the newborn. Pediatr Radiol. 1989;19:169-72.

Lloyd J. The etiology of gastrointestinal perforations in the newborn. J Pediatr Surg. 1969;4:77.

Lucas A, Adrian TE, Christofides N, Bloom SR, Aynsley-Green A. Plasma motilin, gastrin, and enteroglucagon and feeding in human newborn. Arch Dis Child. 1980;55:673-7.

Marsal K, Olofsson P, Lindstrom K. Doppler ultrasonography: physics and techniques. In: Kurjak A. Textbook of perinatal medicine. London: Parthenon Publishing; 1998. p.409-21. 
Martinussen M, Brubakk AM, Vik T, Yao AC. Mesenteric blood flow velocity and its relation to transitional circulatory adaptation in appropriate for gestational age preterm infants. Pediatr Res. 1996;39:275-80.

Maruyama K, Koizumi T, Tomomasa T, Morikawa A. Intestinal blood-flow velocity in uncomplicated preterm infants during the early neonatal period. Pediatr Radiol. 1999;29:472-7.

Mello RA. Embriologia humana. São Paulo: Atheneu; 2000. p.174-87.

Mello RA. Embriologia humana. São Paulo: Atheneu; 2000. p.233-55.

Mercier A, Eurin D, Poulet-Young V, Marret S, Dechelotte P. Effect of enteral supplementation with glutamine on mesenteric blood flow in premature neonates. Clin Nutr. 2003;22:133-7.

Murdoch EM, Sinha AK, Shanmugalingam ST, Smith GC, Kempley ST. Doppler flow velocimetry in the superior mesenteric artery on the first day of life in preterm infants and the risk of neonatal necrotizing enterocolitis. Pediatrics. 2006;118:1999-2003.

Nakamura T, Moriyasu F, Ban N, Nishida O, Tamada T, Kawasaki T, Sakai $\mathrm{M}$, Uchino $\mathrm{H}$. Quantitative measurement of abdominal arterial blood flow using image directed Doppler ultrasonography: superior mesenteric, splenic and common hepatic arterial blood flow in normal adults. J Clin Ultrasound. 1989;17:261-8.

Nowicki P, Edwards R. Effect of $\mathrm{N}^{G}$-monomethyl-L-arginine on postnatal intestinal vascular resistence. Pediatr Res.1992;31:64A.

Nowicki PT, Nankervis CA. The role of the circulation in the pathogenesis of necrotizing enterocolitis. Clin Perinatol. 1994;21:219-34. 
Nowicki PT. Ischemia and necrotizing enterocolitis: where, when, and how. Semin Pediatr Surg. 2005;14:152-8.

Parks DA, Bulkley GB, Granger DN, Hamilton SR, McCord JM . Ischemic injury in the cat small intestine: Role of superoxide radicals. Gastroenterology. 1982;82:9.

Pezzati M, Biagiotti R, Vangi V, Lombardi E, Wiechmann L, Rubaltelli FF. Changes in mesenteric blood flow response to feeding: conventional versus fiber-optic phototherapy. Pediatrics. 2000;105:350-3.

Pezzati M, Dani C, Tronchin M, Fillipi L, Rossi S, Rubaltelli FF. Prediction of early tolerance to enteral feeding by measurement of superior mesenteric artery blood flow velocity: appropriate-versus-small-for-gestational-age preterm infants. Acta Paediatr. 2004;93:797-802.

Pourcelot L. Applications cliniques de l'examen Doppler transcutané. In: Peronneau P, éditeur. Vélocimetrie Ultrasonore Doppler. Paris: Inserm; 1974. p.625-7.

Rand T, Weninger M, Kohlhauser C, Bischof S, Heinz-Peer G, Trattnig S, Popow C, Salzer HR. Effects of umbilical arterial catheterization on mesenteric hemodynamics. Pediatr Radiol. 1996;26:435-8.

Reber KM, Nankervis CA. Necrotizing enterocolitis: preventative strategies. Clin Perinatol. 2004;31:157-67.

Reber KM, Nankervis CA, Nowicki PT. Newborn intestinal circulation. Clin Perinatol. 2002;29:23-39.

Rees D, Palmer R, Hodson H, Moncada S. A specific inhibitor of nitric oxide formation from $\mathrm{L}$-arginine attenuates endothelium-dependent relaxation. $\mathrm{Br} \mathrm{J}$ Pharmacol. 1989;96:418. 
Robel-Tilling E, Knupfer M, Pulzer F, Vogtmann C. Blood flow parameters of the superior mesenteric artery as an early predictor of intestinal dysmotility in preterm infants. Pediatr Radiol. 2004;34:958-62.

Robel-Tilling E, Vogtmann C, Bennek J. Prenatal hemodynamic disturbances pathophysiological background of intestinal motility disturbances in small for gestational age infants. Eur J Pediatr Surg. 2002;12:175-9.

Roll C, Hanssler L. Effect of umbilical arterial catheters on intestinal blood supply. Acta Paediatr. 1998;87:955-9.

Sato S, Ohnishi K, Sugita S, Okuda K. Splenic artery and superior mesenteric artery blood flow: nonsurgical Doppler US measurement in health subjects and patients with chronic liver disease. Radiology. 1987;164:347-52.

Seri I, Abbasi S, Wood DC, Gerdes JS. Regional hemodynamic effects of dopamine in the indomethacin-treated preterm infant. J Perinatol. 2002;22:300-5.

Shah JB, Bracero LA, Gewitz MH, Fish BG. Umbilical artery cateters and blood flor velocities in the superior mesenterio artery: effect of insertion, removal, aspiration, and bolus infusion. J Clin Ultrasound. 1998;26:73-7.

Srinivasan PS, Brandler MD, Souza AD. Necrotizing enterocolitis. Clin Perinatol. 2008;35:251-272.

Stevenson JK, Graham CB, Oliver TK Jr, Goldenberg VE. Neonatal necrotizing enterocolitis. Am J Surg. 1969;118:260-72.

Stuart B, Drumm J, FitzGerald DE, Duignan NM. Fetal blood velocity waveforms in normal pregnancy. Br J Obstet Gynaecol. 1980;87:780-5. 
Taylor KJW, Burns PN, Woodcock JP, Wells PHT. Blood flow in deep abdominal and pelvic vessels: ultrasonic pulsed Doppler analysis. Radiology. 1985;154:487-93.

Van Bel F, Van Zwieten PHT, Guit GL, Schipper J. Superior mesenteric artery blood flow velocity and estimated volume flow: Duplex Doppler US study of preterm and term neonates. Radiology. 1990;174:165-9.

Weir FJ, Fong K, Ryan ML, Myhr T, Ohlsson A. Superior mesenteric artery blood flow velocity measurements in neonates: technique and interobserver reliability. Pediatr Radiol. 1995;25:145-9.

Weir FJ, Ohlsson A, Fong K, Amankwah K, Coceani F. Does endothelin-1 reduce superior mesenteric artery blood flow velocity in preterm neonates? Arch Dis Child Fetal Neonatal Ed. 1999;80:F123-F7.

Yanowitz TD, Yao AC, Werner JC, Pettigrew KD, Oh W, Stonestreet BS. Effects of prophylactic low-dose indomethacin on hemodynamics in very low birth weight infants. J Pediatr. 1998;132:28-34.

Zhang J, Penny DJ, Kim NS, Yu VYH, Smolich JJ. Mechanisms of blood pressure increase induced by dopamine in hypotensive preterm neonates. Arch Dis Child Fetal Neonatal Ed. 1999;81:F99-F104. 